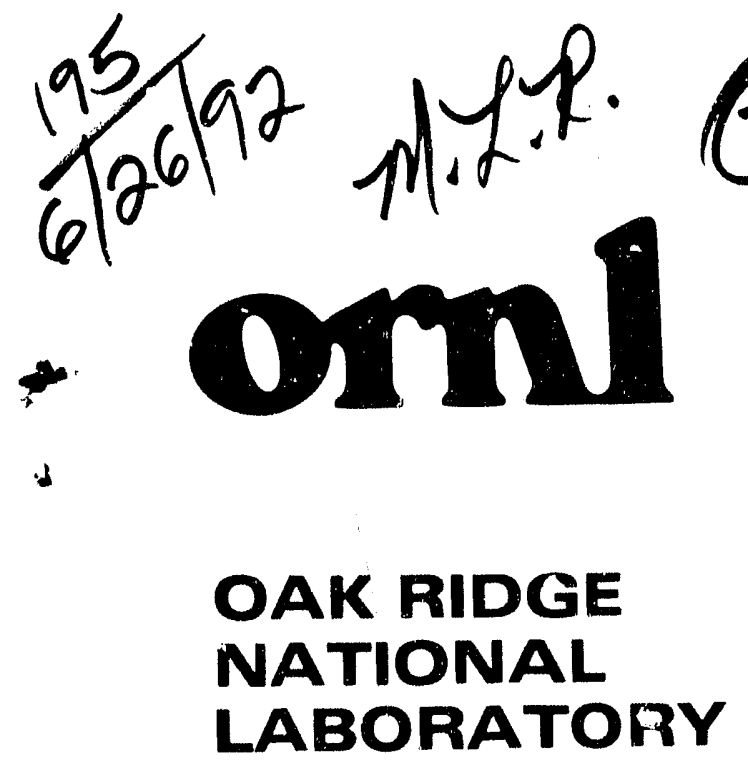

MALTIN MARIETTA
Health and Environmental Risk-Related Impacts of Actinide Burning on High-Level Waste Disposal

C. W. Forsberg 
This report has been reproduced directly from the best availabla copy.

Available to DOE and DOE contractors from the Office of Scientific and Technical Information, P.O. Box 62, Oak Ridge, TN 37831; prices available from (615) 576-8401, FTS 626-8401.

Available to the public from the National Technical Information Service, U.S. Department of Commerce, 5285 Port Royal Rd., Springfield, VA 22161.

This report was prepared as an account of work sponsored by an agency of the United States Government. Neither the United States Government nor any a,jency thereof, nor any of their employees, makes any warranty, express or irnplied, or assumes any legal liability or responsibility for the accuracy, com. pleteness, or usefulness of any information, apparatus, product, or process disclosed, or represents that its use would not intringe privately owned rights. Reference herein to any specific commercial product, process, or service by trade name, trademark, manufacturer, or otherwise, does not necessarily constitute or imply its endorsement, recommendation, or favoring by the United States Government or any agency thereof. The views and opinions of authors expressed herein do not necessarily state or reflect those of the United States Government or any agency thereof. 


\title{
Health and Environmental Risk-Related Impacts of Actinide Burning on High-Level Waste Disposal
}

\author{
C. W. Forsberg
}

May 1992

Prepared by the

OAK RIDGE NATIONAL LABORATORY

Oak Ridge, Tennessee 37831 managed by MARTIN MARIETTA ENERGY SYSTEMS, INC. for the U.S. DEPARTMENT OF ENERGY Under Contract No. DE-AC05-840R21400

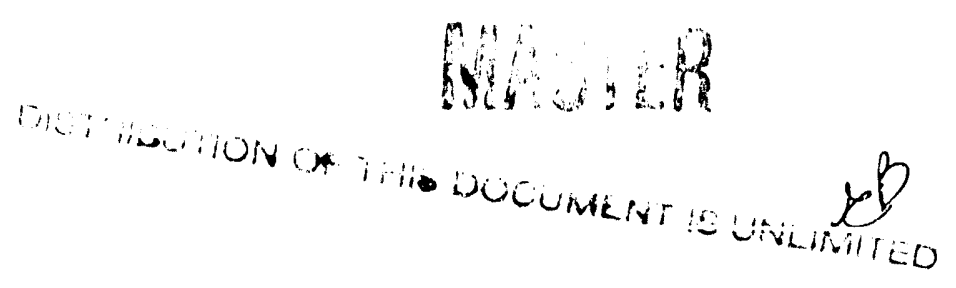




\section{CONTENTS}

LIST OF FIGURES $\ldots \ldots \ldots \ldots \ldots \ldots \ldots \ldots \ldots \ldots \ldots \ldots$

LIST OF TABLES $\ldots \ldots \ldots \ldots \ldots \ldots \ldots \ldots \ldots \ldots \ldots$ vi

EXECUTIVE SUMMARY $\ldots \ldots \ldots \ldots \ldots \ldots \ldots \ldots \ldots$ vii

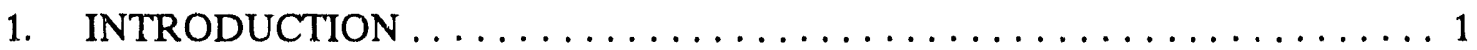

2. REPOSITORY RISK: THEORY AND BACKGROUND $\ldots \ldots \ldots \ldots \ldots \ldots 3$

2.1 OBJECTIVE OF REPOSITORY OPERATION -

STORE UNTIL NONHAZARDOUS $\ldots \ldots \ldots \ldots \ldots \ldots$

2.2 ANALYSIS OF LONG-TERM REPOSITORY PERFORMANCE $\ldots \ldots .3$

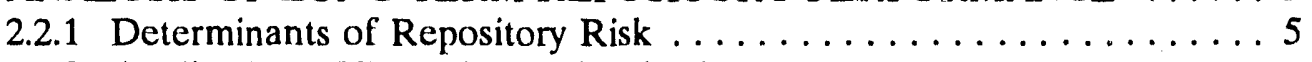

2.2.2 Application of Repository Risk Analysis

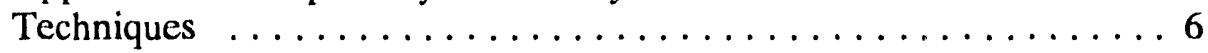

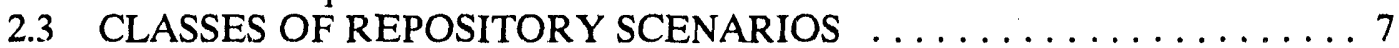

2.3.1 SLAM Scenario ........................ . . 7

2.3.2 Explusive Release Scenario $\ldots \ldots \ldots \ldots \ldots \ldots \ldots \ldots \ldots \ldots$

2.3.3 Human Intrusion Scenario . . . . . . . . . . . . . . . 9

2.4 STATUS OF REPOSITORY PERFORMANCE ASSESSMENT . . . . . . 9

2.4.1 Performance Assessment of the Yucca Mountain Site . . . . . . . . . 9

2.4 .2 Generic SLAM Scenario Assessment . . . . . . . . . . . . 10

2.4.3 Generic Expulsive Release Scenario Assessment . . . . . . . . 11

2.4 .4 Generic Human Intrusion Scenario . . . . . . . . . . . . 12

2.5 ISSUES IN REPOSITORY PERFORMANCE ASSESSMENT . . . . . 13

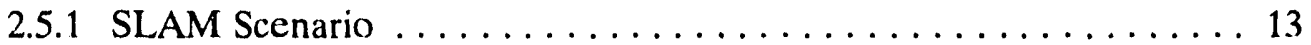

2.5.1.1 Escape of Radionuclides from Waste Package ......... 14

2.5.1.2 Migration of Radionuclides to the Biosphere .......... 14

2.5.2 Expulsive Scenario . . . . . . . . . . . . . . . . 16

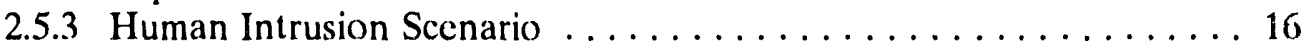

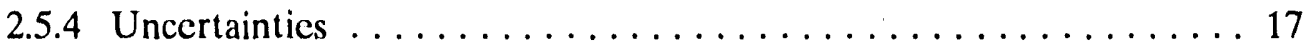

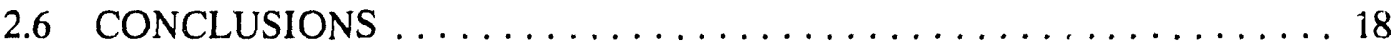

3. SURROGATE MEASURES OF REPOSITORY RISK $\ldots \ldots \ldots \ldots \ldots \ldots 21$

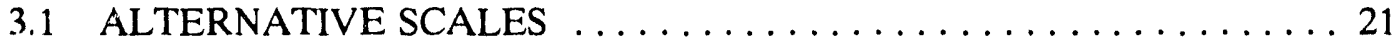

3.1 .1 Radioactivity . . . . . . . . . . . . . . . . 22

3.1.2 Maximum Allowable Radionuclide Concentrations in Water . . . . . 22

3.1.3 Maximum Allowable Radionuclide Concentrations in Air . . . . . . 24

3.1 .4 EPA Repository Standards ................... 24

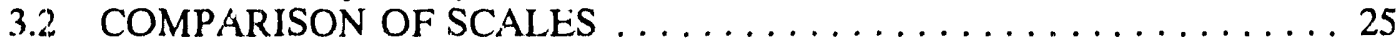

3.3 ANALYSIS .............................. 29

4. POTENTIAL IMPACTS OF ACTINIDE BURNING ON REPOSITORY

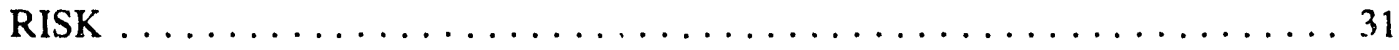

4.1 ACTINIDE BURNING MAY REDUCE UNCERTAINTY

IN LONG-TERM RISK $\ldots \ldots \ldots \ldots \ldots \ldots \ldots \ldots \ldots \ldots \ldots \ldots \ldots$ 
4.2 ACTINIDE BURNING MAY PRODUCE IMPROVED WASTE FORMS THAT HAVE LOWER RELEASE

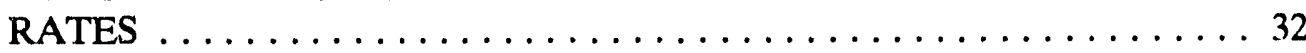

4.3 ACTINIDE BURNING MAY ALLOW FOR IMPROVED MAPNAGEMENT OF TROUBLESOME NONACTINIDES $\ldots \ldots \ldots \ldots 33$

4.4 ACTIIJIDE BURNING MAY GREATLY REDUCE THE POTENTIAL ADVERSE IMPACTS OF COLLOIDS AND COMPLEXES 34

4.5 ACTINIDE BURNING MAY REDUCE TIIE RISK FROM POTENTIAL ADVERSE HYDROLOGIC CONDITIONS . . . . . . 34

4.6 ACTINIDE BURNING MAY REDUCE THE RISK FROM

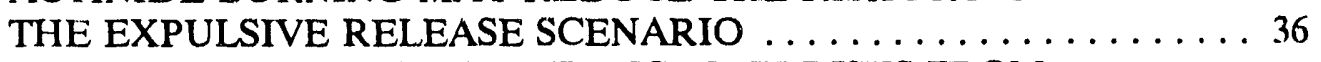

4.7 ACTINIDE BURNING MAY REDUCE THE RISKS FROM

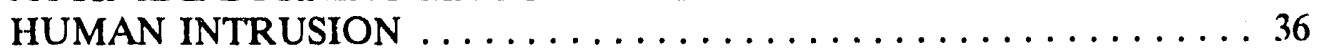

4.8 ACTINIDE BURNING MAY DECREASE RELIANCE ON LONG-TERM PREDICTION OF ENGINEERED BARRIER

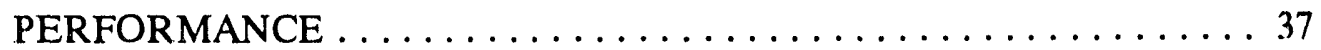

4.9 ACTINIDE BURNING MAY FACILITATE SHOWING COMPLIANCE WITH REGULATIONS $\ldots \ldots \ldots \ldots \ldots \ldots \ldots \ldots$

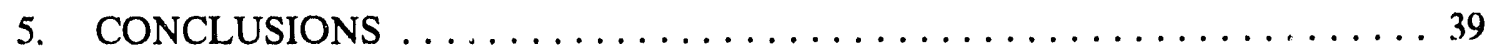

REFERENCES $\ldots \ldots \ldots \ldots \ldots \ldots \ldots \ldots \ldots \ldots \ldots \ldots \ldots \ldots \ldots \ldots \ldots \ldots$

APPENDIX A. NUMERICAL SURROGATE MEASURES OF RISK . . . . 47 


\section{LIST OF FIGURES}

Fig. 1 Potential driving forces for movement of radionuclides from repository and potential barriers to stop movement of radionuclides from repository $\ldots \ldots \ldots \ldots \ldots \ldots \ldots \ldots \ldots$

Fig. 2 Sensitivity of population risks to groundwater flow in

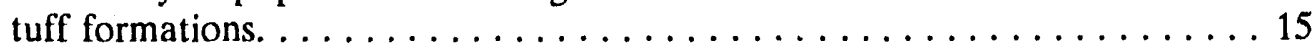

Fig. 3 Hazard of spent fuel versus time measured by different scales. . . . . . 23

Fig. 4 Repository waste inventory as multiple of release limits to environment. ................................ 27

Fig. 5 Residual waste hazard after actinide removal based on EPA repository release limits. 28 


\section{LIST OF TABLES}

Table 1 Cumulative allowable EPA release limits from a HLW/SF repository for 10,000 years after disposal. $\ldots \ldots \ldots \ldots \ldots \ldots$

Table 2 Potential improvements in waste isolation by use of highperformance special waste forms compared to typical HLW

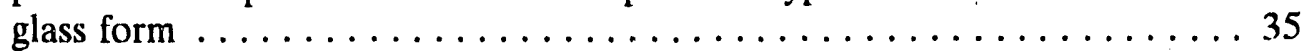

Table A.1 Radioactivity (curies) of one metric ton of pressurized water reactor spent fuel versus time $\ldots \ldots \ldots \ldots \ldots \ldots \ldots \ldots$

Table A.2 Air hazard (cubic meters) of one metric ton of pressurized

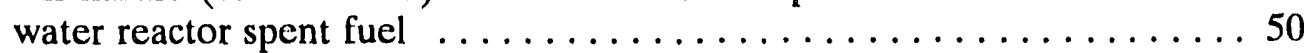

Table A.3 Water hazard (cubic meters) of one metric ton of pressurized

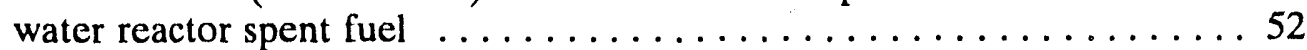

Table A.4 EPA hazard (multiples of EPA release limits) of one metric ton of pressurized water reactor spent fuel 


\section{EXECUTIVE SUMMARY}

The potential health and environmental risk-related impacts of actinide burning for high-level waste disposal were evaluated. Actinide burning, also called waste partitioningtransmutation, is an advanced method for radioactive waste management based on the idea of destroying the most toxic components in the waste. It consists of two steps: (1) selective removal of the most toxic radionuclides from high-level/spent fuel waste and (2) conversion of those radionuclides into less toxic radioactive materials and/or stable elements. Risk, as used in this report, is defined as the probability of a failure times its consequence.

Actinide burning has two potential health and environmental impacts on waste management. Risks and the magnitude of high-consequince repository failure scenarios are decreased by inventory reduction of the long-term radioacti ity in the repository. (What does not exist cannot create risk or uncertainty.) Risk may also be reduced by the changes in the waste characteristics, resulting from sclection of waste forms after processing, that are superior to spent fuel and which lower the potential of transport of radionuclides from waste form to accessible environment. There are no negative health or environmental impacts to the repository from actinide burning; however, there may be such impacts elsewhere in the fuel cycle.

The following specific conclusions can be made with respect to repository risk and actinide burning:

(1.) The most widely accepted measure of repository performance in the scientific community is risk (probability times consequences) as determined by a comprehensive probabilistic risk analysis (PRA).

1.1 The PRA should account for:

the slow-leach and migration (SLAM) scenario, including potential adverse factors such as climatic change, colloids, and complexing agents;

- low-probability, high-consequence expuisive events such as volcanoes; and

deliberate and inadvertent human intrusion. 
1.2 A comprehensive PRA requires an extensive data base and is both complex and time-consuming to complete.

(2.) Existing performance analyses of generic repositories indicate that the risk is small compared with other generally accepted risks and risks from the rest of the nuclear fuel cycle, but such analyses are not available for the proposed United States repository site at Yucca Mountain.

(3.) Actinide removal per se is not expected to significantly reduce the risk from the SLAM scer:srio under currently expected reference conditions. Removal or improved containment (waste forms) of nonactinides may reduce the risk from nonactinides.

(4.) Easily calculable surrogate measures of risk are available, but all of them have significant limitations as compared with a comprehensive PRA.

4.1 Short of a comprehensive PRA, a surrogate measure that expresses risk in terms of multiples of the cumulative repository release limits given in the EPA standard 40 CFR 191 is preferred over other surrogate measures.

(5.) Actinide burning (i.e., removal of actinides from repository wastes) may provide a number of long-term risk-related benefits to the repository:

5.1 Removal of the actinides may reduce the uncertainty in long-term risk by decreasing the maximum consequences from a variety of release scenarios (expulsive events, human intrusion) by about a factor of 1000 from $10^{3}$ to $10^{5}$ years after disposal.

5.2 Actinide burning may eliminate the potential adverse effects of actinide transport by colloids or complexes because the actinides are not in the repository.

5.3 Actinide burning reduces risk from the expulsive release scenario by about a factor of 100 , based on results from existing studies (not specific to the candidate Yucca Mountain site).

5.4 Actinide burning may reduce the risks from human intrusion after several hundred years by (a) reducing by a factor of 1000 the consequences from waste material brought to the surface; and (b) reducing the probability of deliberate intrusion by eliminating the plutonium that may provide the incentive for doing so. 
5.5 Actinide burning may decrease reliance on long-term predictions of engineered-barrier performance by greatly reducing the effective life of the waste.

(6.) Actinide burning requires processing of spent fuel. The processing of spent fuel may provide a number of other long-term risk-related benefits to the repository.

6.1 Actinide burning allows selection of a waste form (borosilicate glass or equivalent) that may not disintegrate under oxidizing repository conditions and which has a much lower release rate for all radionuclides contained in it, as compared with spent fuel. This reduces risk from the SLAM and human intrusion scenarios.

6.2. Actinide burning may allow for improved management of troublesome nonactinides (e.g., ${ }^{14} \mathrm{C},{ }^{99} \mathrm{Tc}$, and ${ }^{129} \mathrm{I}$ ) by either incorporating them into improved waste forms or making them available for transmutation.

(7.) Actinide burning, for the reasons stated previously, may facilitate repository licensing by reducing risk and uncertainty, which should make demonstrating compliance with applicable regulations easier. 


\section{INTRODUCTION}

Actinide burning, also called waste partitioning-transmutation, is an advanced method for radioactive waste management based on the idea of destroying the most toxic components in radioactive waste. Actinide burning consists of two steps: (1) selective removal of toxic radionuclides from spent fuel or high-level waste, and (2) conversion of those radionuclides into less toxic radioactive materials and/or stable nuclides.

Actinide burning is the nuclear equivalent of incineration of hazardous chemical wastes. Incineration destroys many hazardous chemicals and eliminates many long-term risks; however, some hazardous materials such as lead and mercury cannot be destroyed. Like incineration, actinide burning reduces the long-term risks of waste disposal, but not all radionuclides can be destroyed.

The objective of this paper is to identify and discuss one aspect of actinide burning: its risk-related impacts to the high-level waste repository, including various ways to measure that risk. Identification and discussion of risk-related impacts include development of a methodology-an approach-to address these impacts. The analysis presented herein is based on existing information in the literature; thus, most results are qualitative rather than quantitative. Reductions in risk by actinide burning are also dependent upon decisions of which radionuclides to remove from spent fuel and selection of waste form for disposal of remaining radioactive materials after processing.

A number of assumptions will be used in this paper. Hazard and risk will be evaluated on the basis of 10,000 Metric Tons Initial Heavy Metal (MTIHM) of Pressurized Water Reactor (PWR) spent fuel with an average burnup of 33,000 MWd per ton. The choice of fuel or reactor type does not change the conclusions. The analysis considers issues associated with all repositories but focuses on issues specific to repositories in dry (not watersaturated) geologies with oxidizing chemical environments. The proposed repository site at Yucca Mountain in the United States is an example of such a repository site. Last, only longterm repository performance after repository closure (end of waste placement) is considered. 


\section{REPOSITORY RISK: THEORY AND BACKGROUND}

\subsection{OBJECTIVE OF REPOSITORY OPERATION-STORE UNTIL NONHAZARDOUS}

The basic objective of a repository is to store radioactive wastes deep underground until the radioactive materials decay to inconsequential levels. Some radioactive materials remain hazardous for thousands of years; thus, very long storage times are required. No surface facility could be expected to survive for such a long time because of erosion, climate change (ice ages), and other factors. In contrast, typical rocks underground exist for millions of years without change.

To accomplish the objective, most repository designs [FORSBERG 1991] use a multibarrier concept. with manmade and natural barriers to prevent release of radionuclides to the biosphere (Fig. 1). The manmade barriers may include special waste forms, waste packages, overpacks, and repository backfill materials. Each of these creates a barrier to the release of radionuclides to the local geology. Natural barriers may include small groundwater flow and geochemical conditions that reduce solubility and enhance retardation of radionuclides.

\subsection{ANALYSIS OF LONG-TERM REPOSITORY PERFORMANCE}

In scientific and regulatory circles, it is generally accepted that the long-term performance of a repository (i.c., how well it meets the objective stated previously) should be measured by the risk that it represents. Risk is "the potential for realization of unwanted, negative consequences of an event" [ROWE 1977]. It is technically defined in the scientific community as the probability of an event occurring times its consequences. In the context of this paper, the risk is imposed on the general population through the following biospheric pathways:

(1.) drinking water containing radionuclides released from the repository,

(2.) eating foods that contain radionuclides taken from soil or using water containing radionuclides released from the repository, and

(3.) breathing air containing suspended radionuclide particulates released from the repository. 


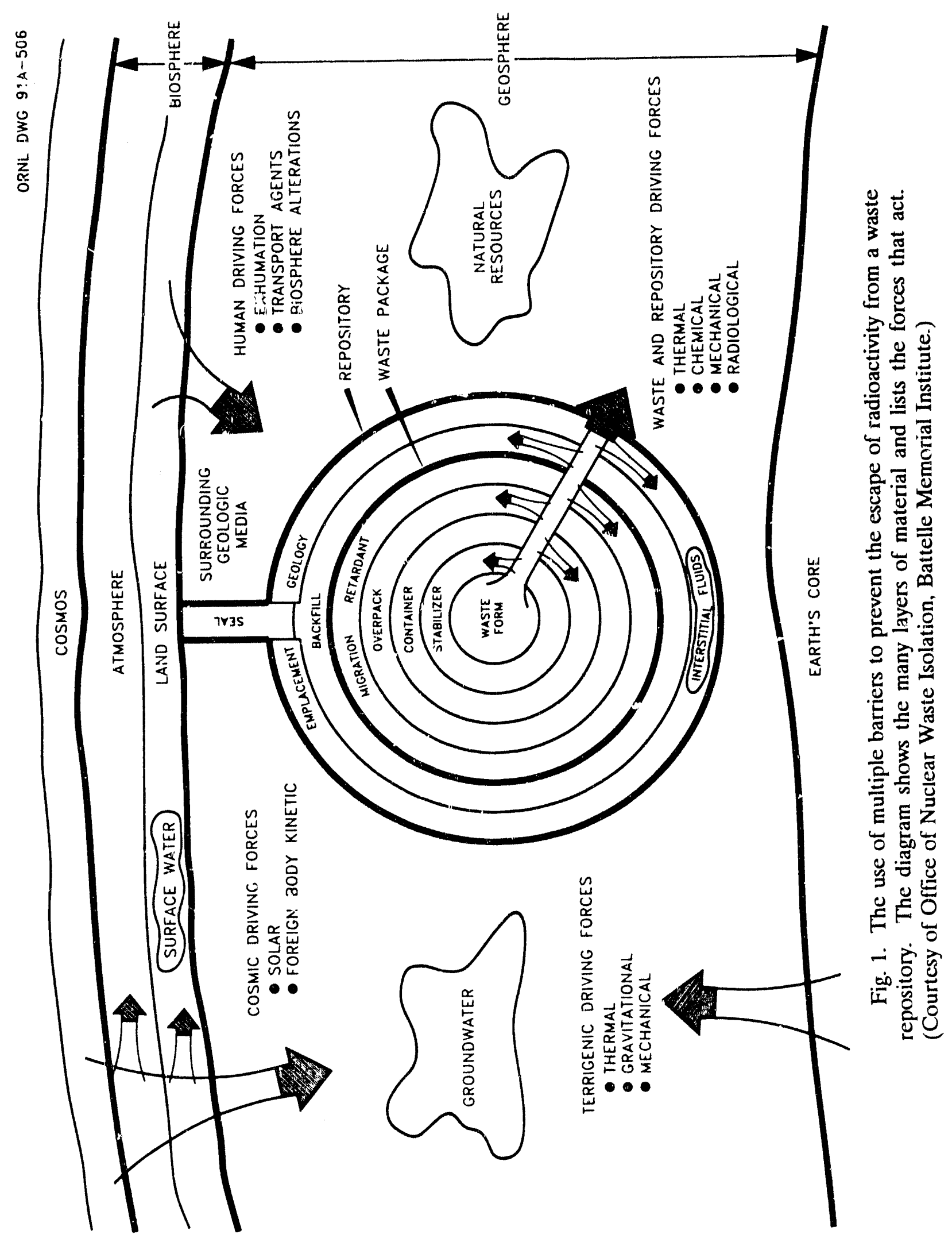


A repository could fail by many different mechanisms, ranging from dissolution and transport of radionuclides by groundwater to a volcano penetrating the repository. Many failure modes are extremely unlikely, but there is the need [HUNTER 1986] to quantify the risk of all potentially significant failure modes to ensure that the repository is safe and that it meets legally defined standards of safety.

An entire set of specific circumstances (e.g., radionuclide inventory, release rate, migration rate, uptake rate) that define the impact of radionuclide releases on the generai public is called a scenario. Many scenarios must be analyzed to determine the risk repr ssented by the repository.

\subsubsection{Determinants of Repository Risk}

Because of the widely varying likelihood of various potential radionuclide release mechanisms, determination of risk must consider both the consequences of a particular scenario, as well as the probability that the scenario will occur [ROWE 1977]. Consequences are typically measured in units of health effects (cancer and genetic damage from radioactivity) and probability as inverse time (e.g., the probability of Scenario $X$ is 1 per 10,000 years).

Based on this, repository risk is defined as the expected consequences to the general public from all radionuclides in the repository, considering all scenarios.

The risk for a single Scenario $\underline{i}$ is defined as:

$$
R_{i}=P_{i} \times C_{i},
$$

where

$$
\begin{aligned}
& R_{i}=\text { risk (health effects/yr) from Scenario } \underline{i}, \\
& P_{i}=\text { probability of Scenario } \underline{i} \text { (1 per year), } \\
& C_{i}=\text { consequences of a Scenario } \underline{i} \text { (health effects). }
\end{aligned}
$$

If Scenario i would result in 100 health effects (HE) in the public but the failure probability of Scenario i failure is 1 in 100 years, the 100-year risk from operation of the repository would be $1 \mathrm{HE}$. If a large number of repositories were built, 99 out of 100 repositories would have no HEs due to this failure mode. One in 100 repositories would have 100 HEs. 
In real repositories, there are multiple potential radionuclide release scenarios (e.g., leaching migration, human intrusion, volcanism). Total risk ( $R$ ) must include all of these as follows:

$$
R=\sum \mathrm{R}_{\mathrm{i}}=\sum\left(\mathrm{P}_{\mathrm{i}} \times \mathrm{C}_{\mathrm{i}}\right)
$$

The consequences $(\mathrm{C})$ of Scenario $\underline{\mathrm{i}}$, any single repository failure mode, can be determined with simplified pathway model represented by the equation

$$
C_{i}=S_{i} \times E_{i} \times M_{i} \times T_{i} \times H_{i},
$$

where

$S=$ source term or inventory, the quantity of the radioactivity in the repository (Ci), which is assumed to be constant for all scenarios;

$E_{i}=$ escape fraction of radionuclides from the waste package to the host rock;

$\mathrm{M}_{\mathrm{i}}=$ migration fraction of radionuclides through the host rock to the biosphere;

$T_{i}=$ transport fraction of radionuclides from where radionuclides enter the biosphere to man;

$\mathrm{H}_{\mathrm{i}}=$ health effects on man per unit of radionuclide received by man (HE/Ci).

The consequences must be calculated for each radionuclide $\mathrm{i}$ in the repository and summed because different radionuclides have different source terms escape fractions, migration fractions, transport fractions, and health effect values. Also, some radionuclides decay to other radionuclides and these must also be followed.

Combining Eqs. 2 and 3 yields the final simplified equation for calculating the risks of a repository.

where

$$
R=\sum_{i}\left(P_{i} \times \sum_{j}\left[S_{j} \times E_{i, j} \times M_{i, j} \times T_{i, j} \times H_{i, j}\right]\right)
$$

$$
\begin{aligned}
& i=\text { release scenario } i \\
& j=\text { radionuclide } j .
\end{aligned}
$$

\subsubsection{Application of Repository Risk Analysis Techniques}

Comprehensive application of Eq. 4 (including time dependent changes in several parameters) is called repository performance assessment or PRA. Such application requires characterization of the behavior of many radionuclides in multiple scenarios along with the 
probability of each scenario. Acquisition of the data required to support this analysis is very time consuming and complex. While development of performance assessment techniques and data acquisition for the Yucca Mountain site are under way [RAMSPOTT 1992], results are not yet available. Further, initial performance analyses are expected to be highly uncertain because our understanding of the site will be unfolding over many years.

As a result, the remainder of this paper will focus on the qualitative analysis of Eq. 4, first in general and then in the context of the impacts of actinide burning.

\subsection{CLASSES OF REPOSITORY SCENARIOS}

For the purposes of this paper, radionuclide release scenarios will be considered in three classes $\rightarrow$ slow-leach-and-migration (SLAM), expulsive release, and human intrusion.

\subsubsection{SLAM Scenario}

The expected ultimate repository failure mode [NAS 1983; HILL 1980] is leaching of radionucides from the waste form by groundwater in the repository followed by flow of the groundwater with dissolved radionuclides in solution to the biosphere. The risk from this SLAM scenario prirnarily depends on the inventory of radionuclides and the escape and migration fractions ( $\mathrm{E}$ and $\mathrm{M}$ ) of each radionuclide from waste package to the environment. If the time for escape and migration of a radionuclide to the biosphere is long compared with the radionuclide half-life, the radionuclide will have decayed to a nonradioactive species and the amount released will be inconsequential.

Following is an outline of the general steps constituting the SLAM scenario.

- Groundwater mus! infiltrate the repository area and contact the waste package.

- The water must penetrate the waste package and contact the waste form. Virtually all planned repositories will use a waste package designed to last several hundred years or more. Any radionuclide with a half-life of decades (e.g., ${ }^{90} \mathrm{Sr}$ and ${ }^{137} \mathrm{Cs}$ ) or less will decay away before expected package failure.

- The groundwater must flow past the waste surface to provide the water to dissolve the radionuclides and transport the radionuclides from the waste package. Backfill materials are often placed around the waste to minimize 
package. Backfill materials are often placed around the waste to minimize flow of water. Furthermore, repository sites are chosen where low water flow is expected.

- The groundwater must dissolve the radionuclides. Some elements such as iodine are potentially highly soluble. Other elements have low solubility. For e'cments with low solubility, large volumes of water (possibly over the long term) are required to dissolve them. Many waste forms such as glass are designed to incorporate the radionuclides in a low-solubility matrix material. In such cases, the matrix material, such as $\mathrm{SiO}_{2}$, must dissolve before the water can dissolve the radionuclides.

- The radionuclides must remain in solution as the water travels from waste to open environment. As dissolved radionuclides travel from waste through waste package materials and through the host rock, the chemical environment changes. Many radionuclides are absorbed on waste package backfill materials and on the host rock, retarding their migration and ultimate release to the biosphere.

- The water must travel from waste package to the biosphere in a time that is short, compared with radionuclide lifetimes. Repository locations are typically chosen for long groundwater travel time to the environment.

The only important radionuclides in the SLAM scenario are those that have the following characteristics-long half-life, relatively soluble in water, and low absorption on rock. Chemical characteristics determine which radionuclides meet the last two conditions and, thus, determine which longer-lived nuclides may leak out. In most studies, the key radionuclides of concern are ${ }^{14} \mathrm{C},{ }^{135} \mathrm{Cs},{ }^{237} \mathrm{~Np},{ }^{99} \mathrm{Tc}$, and ${ }^{129} \mathrm{I}$. At very long times ( $>10^{7}$ years), uranium and daughter products are the dominant radionuclides because most other radionuclides have decayed to nonradioactive elements.

\subsubsection{Expulsive Release Scenario}

In the expulsive release scenario, it is assumed that a major force impacts the repository (volcano, etc.). The result of this force is that some fraction of the waste is 
assumed to be physically moved to the surface in a form that is amenable to dispersion and dissolution.

The basic effect of an expulsive release is to greatly increase the fraction of the inventory that reaches the surface $\left(E_{i}\right.$ times $M_{i}$ in Eq. 4) by bypassing the waste package degradation, waste form dissolution, slow water movement, and radionuclide retardation barriers to radionuclide release that are present in the SLAM scenario. As a result, the potential consequences of this scenario are expected to be relatively large. However, the probability is expected to be relatively small compared to other repository failure modes.

\subsubsection{Human Intrusion Scenario}

The essence of the human intrusion scenario is that the repository is penetrated by the actions of humans on the surface. This scenario might result from two causes. The first cause being inadvertent intrusion. Here, it is assumed that institutional memory concerning the repository is lost and humans drill through the repository searching for resources (e.g., water, petroleum, natural minerals). The second cause is deliberate intrusion, where the intruder is assumed to be aware of the repository contents and is actually seeking them (e.g., noble metals, plutonium).

In either case, there can be two deleterious effects on repository performance. The first is to provide a potential "short circuit" pathway for water to enter or exit the repository [CHANNELL 1991, EPA 1982b, EPA 1985a]. The second deleterious effect is that some amount of waste material could be physically brought to the surface as drilling residuals, similar to what occurs in the expulsive scenario.

\subsection{STATUS OF REPOSITORY PERFORMANCE ASSESSMENT}

\subsubsection{Performance Assessment of the Yucea Mountain Site}

Performance assessment studies are under way on the proposed repository site at Yucca Mountain in Nevada. These studies are not complete, and insufficient information currently exists to evaluate potential repository performance.

The siie is different from any other site that has been considered worldwide, as it is a dry site with the water table below the repository disposal depth. This offers the potential 
advantage (assuming no change in water table levels) of very low water flow through the site, yielding reduced radionuclide release to the environment by the expected dominant repository release mechanism for most repositories-the SLAM scenario. Limited water flow through the site in a vertical direction may occur through migration of water drops by gravity to the water table. Preliminary analysis [APTED 1991, PIGFORD 1990b, RAMSPOTT 1992] of water leach scenarios for Yucca Mountain have emphasized the significance of the same radionuclides $\left({ }^{99} \mathrm{Tc},{ }^{135} \mathrm{Cs},{ }^{129} \mathrm{I}\right.$, and $\left.{ }^{237} \mathrm{~Np}\right)$ that are important in other repository sites, based on limited information that these isotopes will be key isotopes of interest at Yucca Mountain.

The region around Yucca Mountain has several sets of relatively young, small, volcanic cinder cones; thus, expulsive repository failure modes may be a significant consideration in the performance analysis. One study [LINK 1982] evaluated the consequence of specific types of volcanic activity on a repository at Yucca Mountain with either spent fuel (SF) or high-level waste (HLW). The HLW contained the radionuclides less most of the uranium and plutonium. This study assumed that the neptunium, americium, and curium remained with the HLW. For airborne particulate releases, the HEs for HLW were about one-third of those for SF for eruption at 100 years and about one-fourth for eruption at 10,000 years. For nonairborne releases, the cumulative number of HEs for HLW is about one-fourth of that for SF.

\subsubsection{Generic SLAM Scenario Assessment}

There have been numerous studies of repositories and possible mechanisms for repository failure [EPA 1985a, EPA 1982b, SAKERHET 1978, NAS 1983]. These studies have evaluated different geologies, different waste forms, and different repository designs. The analytical studies have been supported by labratory and field experiments in some cases. While the quantitative numbers from these studies depend on repository geology and other factors, most of the studies provide a relatively consistent qualitative perspective on possible repository failure modes. However, it is noteworthy that these studies are heavily focused on the SLAM scenario with minimal consideration of the low-probability, high-consequence scenarios.

The Nuclear Regulatory Commission (NRC) [GOTCHY 1987, NRC 1986] estimated the potential health risks in mortality to the total U.S. population from radioactive waste 
management using assumed generic facilities 'with representative geological characteristics to be $0.004 \mathrm{HEs}$ per GW(e)-year of electricity produced from nuclear power. These health risk estimates are for health impacts over a 1000-year time period, during which the enginecred barriers are major contributors to repository performance. All of the risks are small compared with typical risks from the nuclear fuel cycle (about $1 \mathrm{HE} / \mathrm{GW}(\mathrm{c})$ per year, which are, in turn, small compared with other generally accepted risks by society.

\subsubsection{Generic Expulsive Release Scenario Assessment}

Expulsive events as they relate to repository performance have not been extensively studied. This is largely so because the probability of these events at most repository sites is thought to be so small that the resultant risk is negligible.

The repository risk evaluation performed for the decade-old evaluation of partitioningtransmutation [LOGAN 1980] included an analysis of expulsive scenarios, with both a volcano and a meteorite. The results indicated that the risk from these events was estimated to be $<1 \%$ of that from the SLAM scenario. The primary assumptions were that $7.5 \%$ of the material present at the time of the event was transported to the surface, and the probability of an expulsive release was once every 100 billion years.

The consequences (probability $=1.0$ ) of the expulsive scenario for standard HLW was a factor of 10 to 100 greater than those of the SLAM scenario. Removal of the minor actinides from the HLW reduced the consequences of the expulsive scenario by at least an order of magnitude. The consequences from an expulsive scenario with SF compared to HLW are an order of magnitude larger because of the plutonium inventory. Isotopes of plutonium and americium dominate the risk for events occurring from 1,000 to 10,000 years. Beyond 10,000 years, radium and thorium decay products are dominant. These results are consistent with the earlier conclusions of [CLAIBORNE 1974].

There has been some analysis of expulsive events such as Mount St. Helens volcanic eruption through a waste repository [BROWN 1982]. Conclusinns from this work for expulsive releases occurring more than 1000 years after closure are as follows:

(1.) The actinides are the dominant contributor to the risk with americium and plutonium, dominating risks to $10^{5}$ years with actinide daughter products radium and thorium controlling risks between $10^{5}$ and $10^{6}$ years. 
(2.) For HLW (99.5\% removal of uranium and plutonium), the hazard of the natural radioactivity in the rock exceeds the hazard of the waste beyond 2000 years after reactor discharge.

(3) The doses from the nonactinides are less than those from the natural radioactivity in the volcanic rock.

These results appear to be consistent with those in [LOGAN 1980].

Although mentioned in the EPA report [EPA 1985a], risk from a volcano is not presented in the results. However, combining the fraction expelled and probability that are given in the text with calculated results given in another EPA report [EPA 1982b] yields a value of about $0.9 \mathrm{HE}$ from volcanoes over 10,000 years for the generic tuff repository. Isotopes of americium and plutonium dominate the calculated consequences from this scenario.

While much additional risk assessment work is required to provide quantitative risk numbers, the limited work to date supports the conclusion that the actinides dominate risks for expulsive failure scenarios for a repository at Yucca Mountain. The actual risk of such events is thought to be low due to the expected low probability of expulsive volcanic activity, but there are large uncertainties in estimates of the probabitities of volcanic events.

\subsubsection{Generic Human Intrusion Scenario}

Significant efforts to analyze human intrusion scenarios are under way domestically and internationally [NEA, 1989], but only limited results from scveral early studies are available [EPA 1982b, EPA 1985a]. As in the expulsive release scenario, human intrusion has the net effect of potentially increasing the fraction of the inventory transported to the biosphere and the rate at which it is transported. Addressing this scenario is difficult because of the need to predict the likelihood of human actions in the distant future, as well as predicting the consequences of their actions.

Inadvertent intrusion involves drilling a well into or through the repository, presumably in search of natural resources. There are three mechanisms by which inadvertent intrusion can increase repository risk [EPA 1985a]-intersecting a waste canister and bringing radioactive material to the surface, bringing groundwater containing dissolved radionuclides to the surface, and providing a "short circuit" for groundwater to infiltrate the repository and then to flow to the environment. 
The first mechanism is expected to dominate this scenario for an unsaturated repository horizon. The risk from this mechanism was estimated to be $0.44 \mathrm{HE}$ over 10,000 years [EPA 1985a], and this results from isotopes of plutonium and americium. The second mechanism is expected to be negligible for an unsaturated repository because very little contaminated water could exist to be removed to the surface. The third mechanism has been found to be negligible in all cases simply because it docs not represent enough of a pathway to make a significant contribution.

The SLAM scenario was found to be negligible, as compared with the inadvertent human intrusion scenario for a generic tuff repository. Inadvertent human intrusion was found to be about one-sixth the risk from faulting, which was the scenario with the highest calculated risk. Soluble radionuclides dominate the faulting scenario.

Deliberate intrusion could have more severe repercussions than inadvertent intrusion. Deliberately sceking out the SF for its constituents would bring much larger amounts of debris to the surface and would probably involve many penetrations that may provide a significant shortening of the water migration pathway (possibly even a circulating loop). Estimates of the risk from deliberate intrusion are not available.

\subsection{ISSUES IN REPOSITORY PERFORMANCE ASSESSMENT}

\subsubsection{SLAM Scenario}

The baseline SLAM scenario will constitute the expected behavior of the repository. This is because the repository is known (or must be assumed) to be infiltrated by water, the waste packages are degraded at some rate, and a small fraction of the radionuclicies are transported to the biosphere. This class of scenarios is emphasized in most repository performance assessments, often to the exclusion of other scenario classes.

The general issue in the SLAM scenario is the probability of other factors that would significantly increase the consequences of this baseline SLAM scenario. The following sections identify the primary factors beneficially and adversely affecting the repository-related parameters in Eq. 4. The existence of the adverse factors would tend to favor the processing of SF with removal of radionuclides such as the actinides ${ }^{99} \mathrm{Tc}$, and ${ }^{22} \mathrm{I}$ from the fucl and/or use of better waste forms. 


\subsubsection{Escape of Radionuclides from Waste Package}

Escape $(\mathrm{E})$ of radionuclides from the waste package is expected to be slow because there is relatively little groundwater to penetrate the package and transport radionuclides in an unsaturated rock. However, there are other factors that v ould adversely impact these beneficial conditions. These factors include:

(1.) The potential for climate change, resulting in greatly increased water infiltration rates. An example of the impacts of increased water flow is given in Fig. 2 [EPA 1985a].

Some radionuclides (such as ${ }^{14} \mathrm{C}$ ) are believed to be present in significant quantities on the surface of the nuclear fucl and will be released relatively quickly upon contact with water.

(2.) The presence of oxidizing conditions that are detrimental to the integrity of spent oxide nuclear fuels relative to other waste forms.

(3.) Difficulties in predicting the behavior of engineered barriers (e.g., metal alloys) for thousands of years.

\subsubsection{Migration of Radionuclides to the Biosphere}

Migration (M) of radionuclides from the waste package to the biosphere is expected to be slow because of low water velocity, low water volume, and the retardation of many radionuclides by sorption on the host rock. Factors that would negatively impact migration include:

(1.) the potential for climate change resulting in greatly increased water velocity and volume (Fig. 2);

(2.) the potential for "short circuit" water migration pathways resulting from fractures;

(3.) oxidizing conditions that result in a few radionuclides being in chemical forms thought not to be retarded relative to the groundwater movement [AHN 1992]; and

(4.) the potential presence of physicochemical phenomena (e.g., colloids, complexants) that negate the beneficial effects of retardation for most radionuclides. 
ORNL DWG $91 \mathrm{~A}-507$

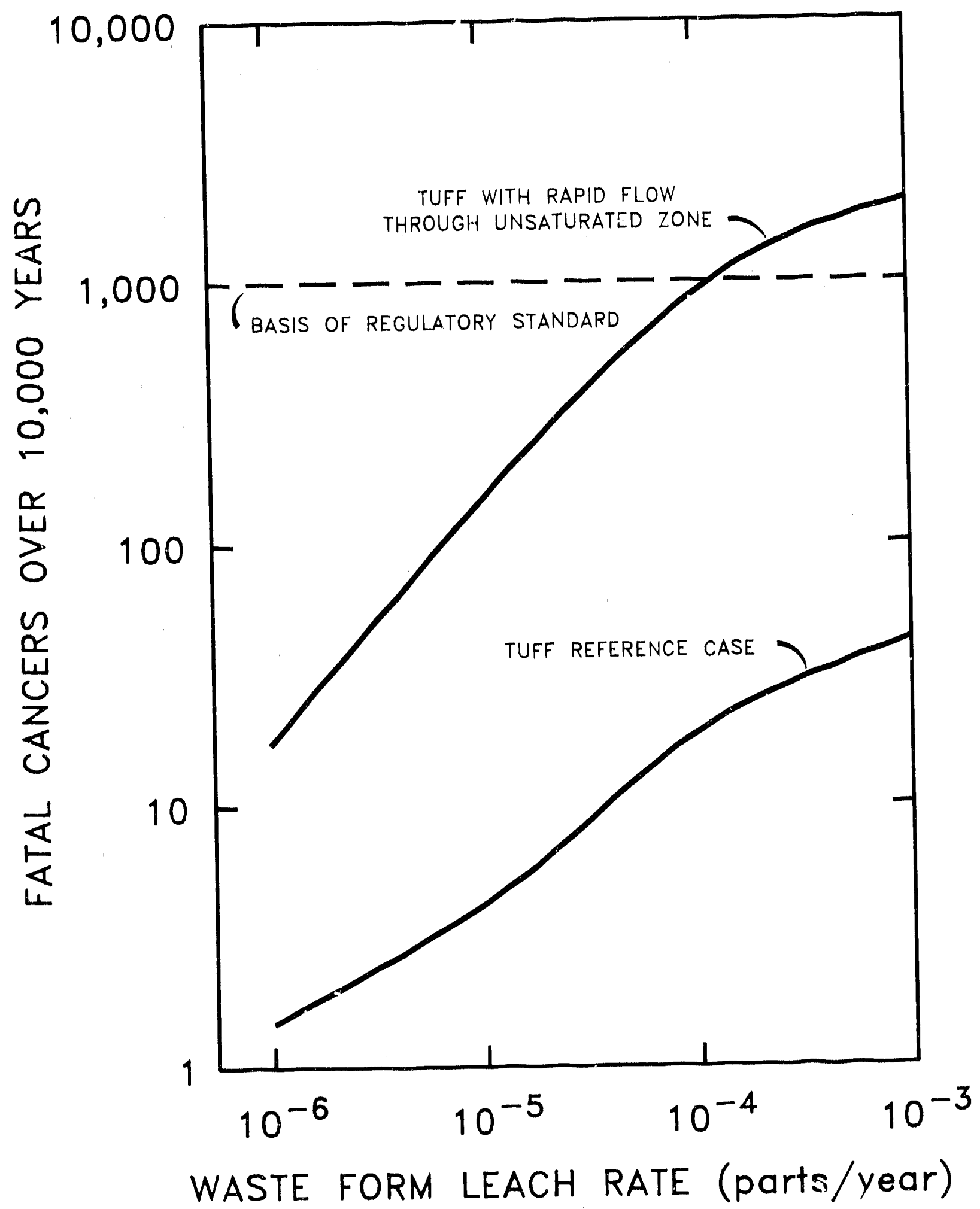

Fig. 2. Sensitivity of population risks to ground water flow in tuff formations. 
Colloids can suspend microscopic particles that would otherwise be insoluble and allow them to be transported by moving water [NUTTALL 1991]. The actinides have a significant affinity for forming colloids. The enhanced transportability of the particles may be offset by the size of the colloid, which could be too large to move through the fractures and pores of the host rock.

The solubility of many radionuclides, including the actinides, can be greatly increased by complexing with other chemical species. Both organic and inorganic complexes can be formed and result in a true solution that may migrate much more readily than the radionuclide alone.

\subsubsection{Expulsive Scenario}

Although there are many issues associated with expulsive scenarios, two are expected to be dominant. The first is the probability of the scenario occurring. In LOGAN (1980), an expulsive event was assumed to occur about every 100 billion years in the reference salt repository. A value of one event every 33 million years was used in EPA 1985a. To the extent that this probability is increased or decreased, the risk from expulsive events will change in proportion.

The second major issue is the fraction of the waste expelled to the surface. The previous study [LOGAN 1980] assumed $7.5 \%$ of the waste material present at the time of the event was instantly transported to the biosphere. The EPA [EPA 1985a] used a value of $0.04 \%$. The consequences and risk of the expulsive scenario are directly proportional to this value which is highly sensitive to the type of volcanic activity.

\subsubsection{Human Intrusion Scenario}

The major issue concerning human intrusion is determining the probability that a particular scenario (i.e., how many penetrations, deliberate or inadvertent, how much material is brought to the surface) occurs. This determination is not amenable to analysis using physical laws but must rely on assumptions and beliefs concerning the motives of potential intruders and the efficacy of institutional controls. 


\subsubsection{Uncertainties}

Uncertainties in the prediction of repository performance are a direct result of the very long time frames of repository operation and the inherent inability to completely characterize the site geology without compromising its function. As a recent National Academy of Science [NAS 1990a] report stated about predicting repository performance, the geologic hazards "will remain uncertain no matter how much additional information is gathered."

The essence of uncertainty is that no matter how much information acquisition and analysis is undertaken, it will always be necessary to allow for the fact that the results could seriously be in error because of the occurrence of the unexpected (e.g., a low-probability event actually occurs) or the unknown (e.g., an unknown chemical reaction results in greatly increased risks).

Uncertainty can be incorporated into a performance assessment by assuming that the input parameters are represented by distribution functions rather than singie values. For example, the expected retardation factor for plutonium may be 1000 , but the calculation would use values ranging from 100 to 10,000 , with the extremes of the range having a much lower probability than the expected value. Thus, probabilities are associated with the overall scenario, as well as with each parameter characterizing the scenario.

The central issue is whether the uncertainty is too great, and, if so, how can it be reduced to acceptable levels? Stated another way, the issue is whether having a small but significant probability of extremely large impacts from the repository is acceptable. Societics have shown strong preferences for avoiding high-consequence failures in any kind of enterprise [HONENEMSER 1990]. Regulatory authorities [EPA 1985c] have also reflected this preference of society, as evident in the environmental standards for waste disposal, which require decreasing probabilities of occurrence for failure modes with higher consequences. In previous sections, some of the adverse factors that could potentially cause significant uncertainty are discussed. In most cases, the uncertainty would result from the adverse factors allowing the most toxic components of the waste-the actinides-to be released in much larger amiounts than expected. Thus, in the present context, the issue becomes whether it is desirable or necessary to remove the actinides to cap the uncertainty in repository risk at a more acceptable level. 


\subsection{CONCLUSIONS}

(1.) The preferred measure of repository performance is risk as determined by a comprehensive PRA on a specific repository site. The analysis should account for:

- The SLAM scenario, including potential adverse factors (e.g., climatic change, colloids, complexing agents);

- low-probability, high-consequence expulsive events (e.g., volcanoes); and

- human intrusion, both inadvertent and deliberate.

(2.) Existing performance analyses indicate that the risk from a repository is very small, but such analyses are not available for the Yucca Mountain candidate repository site.

- The risk from the nuclear fuel cycle is small compared with other generally accepted risks by society, and the risk from the repository is expected to be less than $1 \%$ of the fucl cycle risk over 1000 years. Longer term risks are expected to be equivalent or less than the uranium ore deposits mined for the original fuel.

- Performance assessment studies for generic and site-specitic r positories have been performed in the past, but none encompass the specific parameters of the Yucca Mountain site.

- Performance analysis of the Yucca Mountain candidate repository site is under way. Some scenarios have been analyzed based on existing limited data [RAMSPOTT 1992]. Final results are years away because of the need for much more site-specific data.

(3.) The following factors were identified as having the potential to adversely affect the long-term performance of the Yucca Mountain site:

- potential adverse hydrologic conditions such as substantially increased water infiltration rates ard "short circuit" water migration pathwe ys (naturally occurring or result ng from intrusion),

- detrimental effects of oxidizing conditions on the integrity of spent nuclear fuel,

- presence of ${ }^{14} \mathrm{C}$ on the surface of spent nuclear fuel assemblies and the high solubility and low retardation of other radıonuclides under oxidizing conditions, 
- reduced actinide retardation resulting from the effects of colloids and complexes,

- difficulty in predicting the behavior of engineered materials for long time periods,

- expulsive release scenarios which might be a significant contributor to the total risk because of the volcanic origins of the site, and

- potential human intrusion into the repository for recovery of plutonium in the SF.

(4.) Uncertainty in long-term repository performance is inescapable, and the upper range of reasonable uncertainty may be the point at which acceptability is determined. 


\section{SURROGATE MEASURES OF REPOSITORY RISK}

For studies on advanced waste management options such as actinide burning, there is a need to measure the risk-related benefits for any repository. Because a PRA-based analysis is very complex and demands extensive site-specific data, surrogate measures of risk are typically used. Many such measures have been proposed [POSTON 1978, VOSS 1979, SMITH 1980]. Ideally, such surrogate measures of risk should be broadly applicable to all repositories and based on current knowledge. Preferred surrogate measures of risk are discussed herein.

\subsection{ALTERNATIVE SCALES}

Four different scales have been used historically as surrogate measures of repository risk for different radionuclides in SF/HLW. As surrogate measures of risk, each scale excludes those components of risk that are specific to a particular repository site. As such, they provide a generic approach to evaluate risk-related impacts of actinide burning to repositories independent of specific sites. The site-specific factors that are ignored include (1) the probability of repository failure by each failure mode (P) and (2) the escape and migration fractions $(\mathrm{E}$ and $\mathrm{M})$ for each radionuclide from the repository to the environment. These site-specific factors are often of critical importance. Most of these surrogate measures of risk are more or less proportional to the consequences of direct release of radioactive materials to the biosphere by different pathways (i.e., toxicity). The scales are:

(1.) radioactivity (curies),

(2.) quantity of water necessary to dilute radionuclides down to the concentration of the radionuclides allowed in water to be discharged to the environment (cubic meters of water),

(3.) quantity of air necessary to dilute radionuclides down to the concentration of the radionuclides allowed in air to be discharged to the environment (cubic meters of air), and

(4.) allowable release of radionuclides from a waste repository as a multiple of the EPA limits for radionuclide releases (dimensionless). 
The four graphs in Fig. 3 show the hazards of spent fuel (SF) versus time as measured with the four scales described previously. The data were calculated using the ORIGEN2 code [CROFF 1980]. In each graph, the hazard of the SF is broken into three fractions-fission products, actinides, and activation products. The actinides include $\mathrm{U}, \mathrm{Np}, \mathrm{Pu}, \mathrm{Am}, \mathrm{Cm}$, and daughter products. The activation products are radioactive wastes generated by activation of nonradioactive materials in the nuclear reactor. Because the analysis addresses repository issues, SF hazards are not shown until several decades after reactor discharge. At shorter times, fission products, many with short half-lives, are the dominant hazard, as measured by most scales. Appendix A provides additional detail.

\subsubsection{Radioactivity}

The simplest measure of the relative hazards of radionuclides is the curies of each radionuclide. This is a direct measure of instantaneous Source (S) term in the risk equation for repositories. This unit of measure is easy to understand, involves few assumptions, and is directly related to other properties of radioactive materials such as heat generation. In the first $100+$ years, the dominant hazards measured in curies are from the fission products ${ }^{90} \mathrm{Sr}$ and ${ }^{137} \mathrm{Cs}$. Thereafter, the actinides are the dominant hazard. Americium-241 is the dominant hazard to $1000+$ years with the longer-term hazard controlled by ${ }^{239} \mathrm{Pu}$ and ${ }^{240} \mathrm{Pu}$.

\subsubsection{Maximum Allowable Radionuclide Concentrations in Water}

Historically, the most commonly used measure of relative hazards of radionuclides is the quantity of water needed to dilute each radionuclide to the maximum allowable concentrations in water released to the environment [NRC 1975]. This is a health-based approach in which the quantity of radionuclides allowed in the water depends on the biological effects from direct ingestion of a soluble species. With $\mathrm{SF}^{90} \mathrm{Sr}$ and ${ }^{137} \mathrm{Cs}$ are the dominant hazards for the decades with ${ }^{241}$ Am the dominant hazard from a few hundred years to $1000+$ years. Beyond this timeframe, ${ }^{239} \mathrm{Pu}$ and ${ }^{240} \mathrm{Pu}$ are the dominant hazards.

As a surrogate measure of repository risk, this scale accounts for the repository source term (S), health effects to man $(\mathrm{H})$ assuming that radionuclides reach man in drinking water, and one mode of transport $(\mathrm{T})$ of radionuclides in the environment. It does not account for repository-specific performance factors (P, E, M). Most performance assessments of 

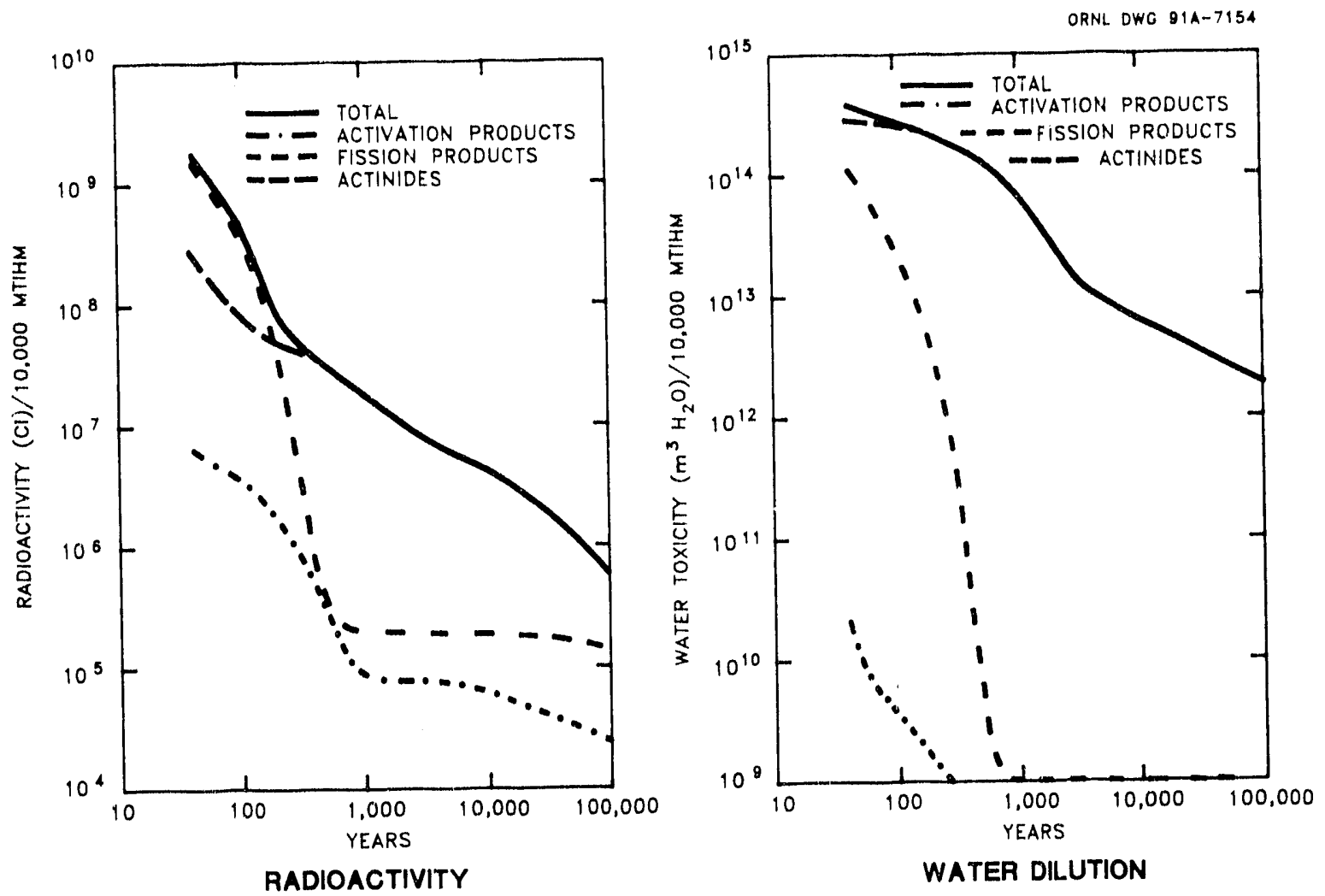

WATER DILUTION

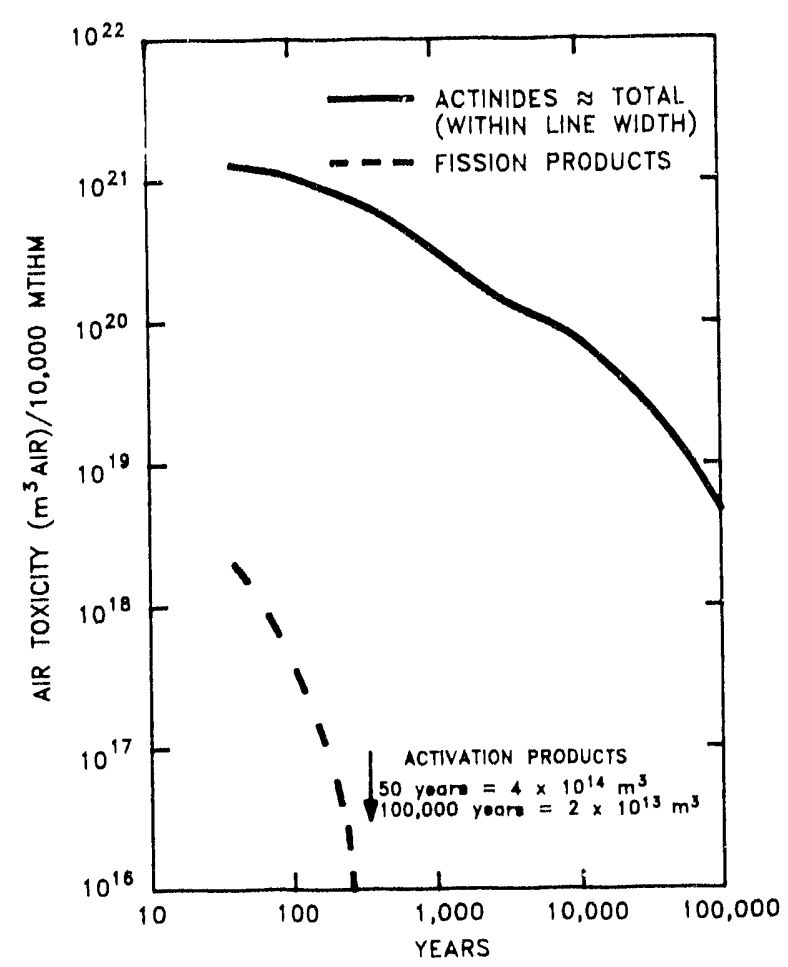

AIR DILUTION

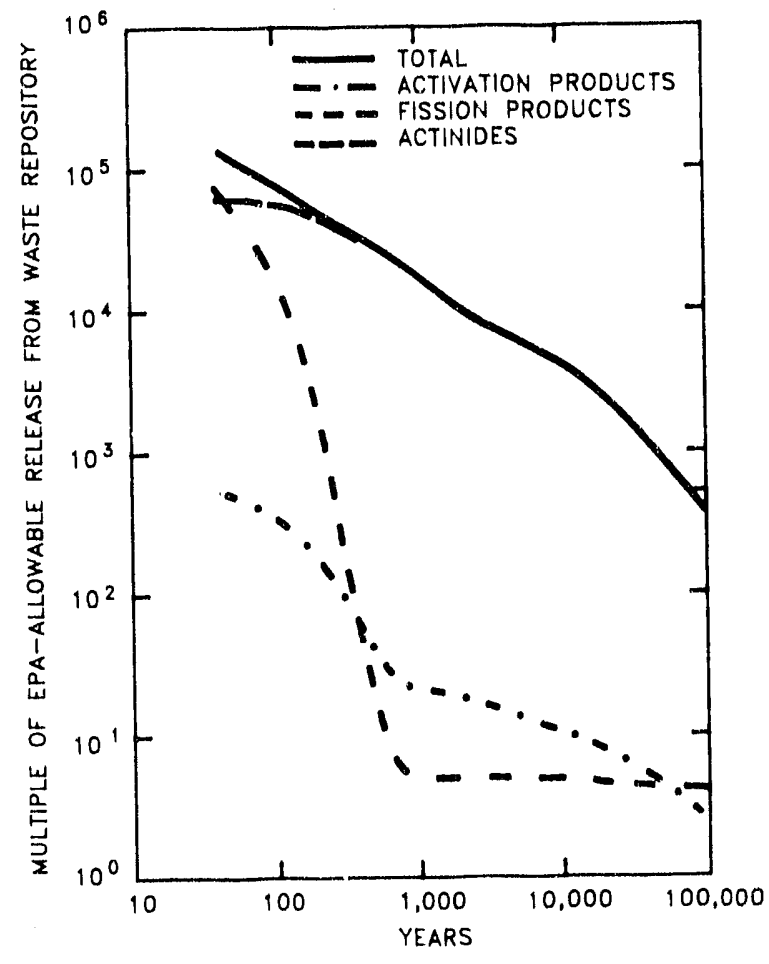

EPA STANDARD

Fig. 3. Hazard of spent fuel versus time measured by different scales. 
repository risk [NAS 1983] from the SLAM scenario differ significantly from this surrogate measure of risk in that such repository assessments do not show ${ }^{241} \mathrm{Am}$ and ${ }^{239} \mathrm{Pu}$ as radionuclides of concern. Such detailed models of repository performance show decay of these radionuclides before reaching the biosphere because of adsorption on rock from groundwater. This measure is better for radionuclides with very long half-lives and chemistry, such as ${ }^{237} \mathrm{~Np}$, that result in a lower retardation on rock surfaces.

\subsubsection{Maximum Allowable Radionuclide Concentrations in Air}

An alternative measure of relative hazards of radionuclides is the quantity of air needed to dilute each radionuclide to the maximum allowable concentrations accepted in breathable air [NRC 1975]. This approach is equivalent to the previously mentioned water standards, except that the radioactivity enters the body via the lungs rather than the stomach. With this measure, the actinides are the dominant hazards at all times of interest. For most of the first 1000 years, ${ }^{241} \mathrm{Am}$ is the dominant risk; at longer time frames, ${ }^{239} \mathrm{Pu}$ is the primary isotope of concern.

As a surrogate measure of repository risk, this scale accounts for the repository source term (S) and health effects to man $(\mathrm{H})$ assuming that radionuclides enter the environment in the air. It does not account for repository specific performance factors $(P, E, M)$. This surrogate measure of risk identifies the same radionuclides of concern as specific detailed repository models of "unexpected" repository failure modes (volcano, drilling) because "unexpected" repository failure modes transport particles of waste to the surface where resuspension in the air can be an important pathway.

\subsubsection{EPA Repository Standards}

The fourth and newest surrogate measure of risk is based on the EPA limits on allowable releases from a repository [EPA 1985c]. Surrogate risk is measured as a multiple of allowable EPA releases from a repository over a period of 10,000 years. EPA's approach [EPA 1985a, EPA 1985b] to creating this standard was first to define acceptable risks from the repository. With the defined levels of safety, allowable releases of radionuclides were calculated for three major pathways: (1) air (volcanic activity), (2) land surface (drilling fines brought to earth's surface), and (3) groundwater. For each major pathway, there are many 
specific pathways of which EPA studied 30. For example, the groundwater pathways from repository to man included uptake of radioactivity by man via (1) drinking water; (2) eating fish; (3) eating three types of foods grown by irrigation: surface crops, milk, and beef; (4) breathing air contaminated by resuspension after irrigation; and (5) standing on ground contaminated by irrigation.

For each of the above pathways, EPA calculated how much of each radionuclide would have to be released to the aceessible environment (air, ground, or water) to cause the equivalent of 1000 premature: deaths over 10,000 years. Using the most restrictive cases, this modeling approach determined the numerical release limits for each radionuclide from the repository. Release of multiple radionuclides is taken into account through the sum of the fractions rule in which

$$
\begin{aligned}
& \mathrm{Q}_{1} \\
& \mathrm{~A}_{1}
\end{aligned}+\frac{\mathrm{Q}_{2}}{\mathrm{~A}_{2}}+\underset{\mathrm{A}_{3}}{\mathrm{Q}_{3}}+\ldots<1,
$$

where

$Q_{j}=$ cumulative predicted releases to the accessible environment of radionuclide $j$,

$A_{j}=$ allowable releases to the accessible environment of radionuclide $j$.

This methodology parallels how risk is determined for a repository except that all site-specific information $(\mathrm{P}, \mathrm{E}, \mathrm{M})$ is excluded. Table 1 shows the allowable releases. Figures 4 and 5 [CROFF 1990] show the results of using this measure on spent PWR fuel and wastes from the reprocessing of this fuel with removal of most of the actinides (see Chapter 4).

Based on this measure, the risk-dominant near-term hazards are ${ }^{137} \mathrm{Cs},{ }^{90} \mathrm{Sr}$, and ${ }^{241} \mathrm{Am}$. Between 100 and 1000 years, ${ }^{241}$ Am controls the hazard. For longer time periods, ${ }^{239} \mathrm{Pu}$ and ${ }^{240} \mathrm{Pu}$ are the dominant hazards.

\subsection{COMPARISON OF SCALES}

It is important to understand the different assumptions and beliefs that underlie these scales [NAS 1990b) and potential implications for actinide burning. Each of these scales was constructed for a particular set of conditions: water standards where water contamination is a concern, air standards where air contamination is a coneern, and repository standards where waste management failures are a concern. 
Table 1. Cumulative allowable EPA release limits from a HLW/SF repository for 10,000 years after disposal ${ }^{\star}$

\begin{tabular}{|c|c|}
\hline Radionuclides & $\begin{array}{c}\text { Allowable releases per } \\
1000 \mathrm{M}^{\prime} \mathrm{TIHM} \text { in SF } \\
\text { or HLW equivalent }{ }^{\mathrm{b}} \\
(\mathrm{Ci})\end{array}$ \\
\hline Americium-241 or -243 & 100 \\
\hline Carbon-14 & 100 \\
\hline Cesium- 135 or -137 & 1,000 \\
\hline Iodine-129 & 100 \\
\hline Neptunium-237 & 100 \\
\hline Plutonium-238, $-239,-240$, or -242 & 100 \\
\hline Radium-226 & 100 \\
\hline Strontium-90 & 1,000 \\
\hline Technetium-99 & 10,000 \\
\hline Thorium-230 or -232 & 10 \\
\hline Tin-126 & 1,000 \\
\hline Uranium-233, $-234,-235,-236$, or -238 & 100 \\
\hline $\begin{array}{l}\text { Aryy other alpha-emitting radionuclide with } \\
\text { half-life greater than } 20 \text { years }\end{array}$ & 100 \\
\hline $\begin{array}{l}\text { Any other radionuclide with a half-life } \\
\text { greater than } 20 \text { years that does not } \\
\text { emit alpha particles. }\end{array}$ & 1,000 \\
\hline
\end{tabular}

a Ref. [1985c].

b For mixture of radionuclides, "sum of the fractions rule" is used with the above numerical limits. With this rule, it is necessary to determine the sum of fractions by dividing the quantity of each radionuclide released to the accessible environment over the first 10,000 years per 1000 MTIHM by the appropriate limit and adding the resulting values. Example: assume total calculated releases are 500 curies of ${ }^{90} \mathrm{Sr}$ and 40 curies of ${ }^{241} \mathrm{Am}$ over a period of 10,000 years per 1000 MTIHM. For the ${ }^{90} \mathrm{Sr}$ fraction, $500 / 1000=0.5$; for the ${ }^{241} \mathrm{Am}$ fractions, $40 / 100=0.4$; thus, the sum of the fractions is 0.9 . Because the sum is less than 1.0 , the repository meets EPA allowable release criteria. 


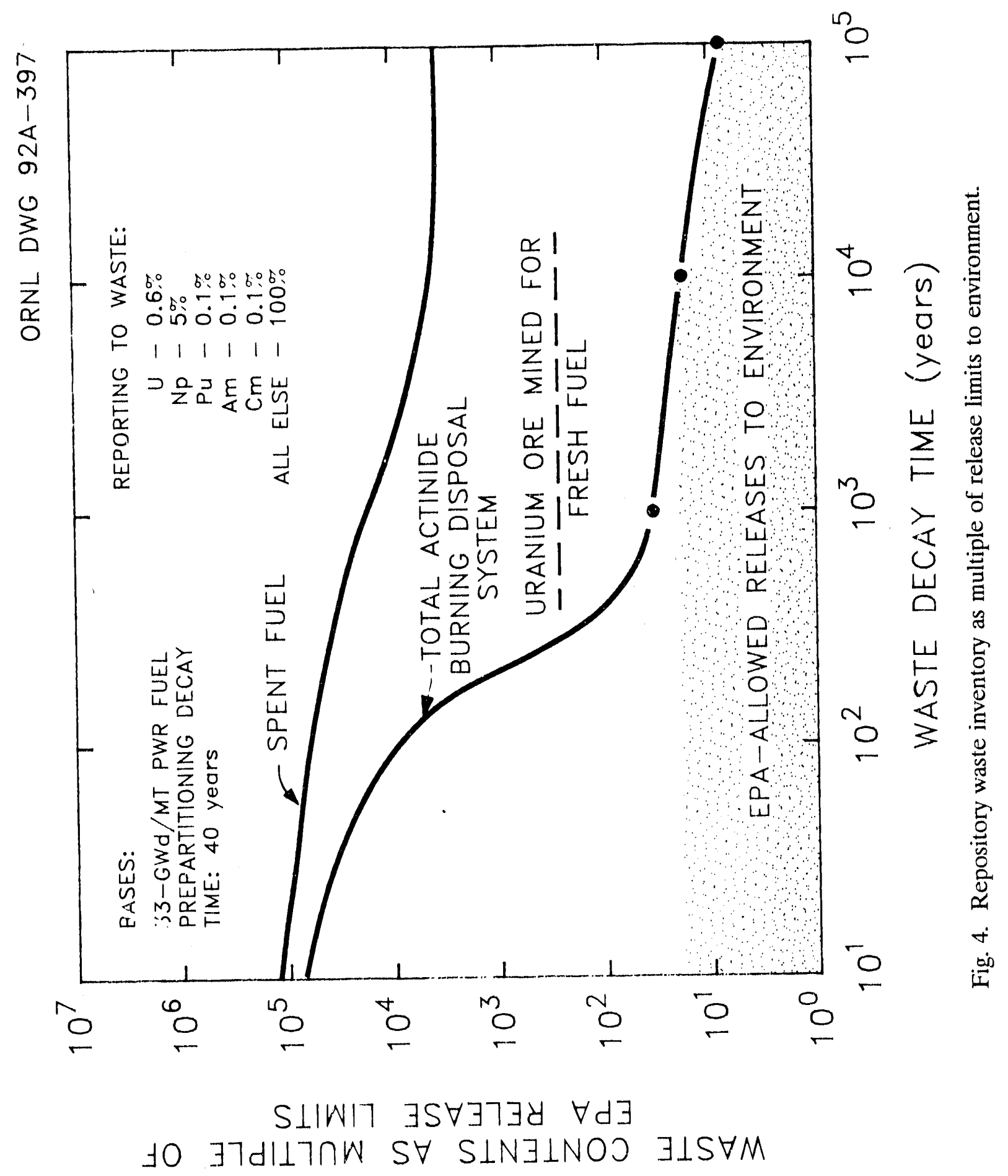




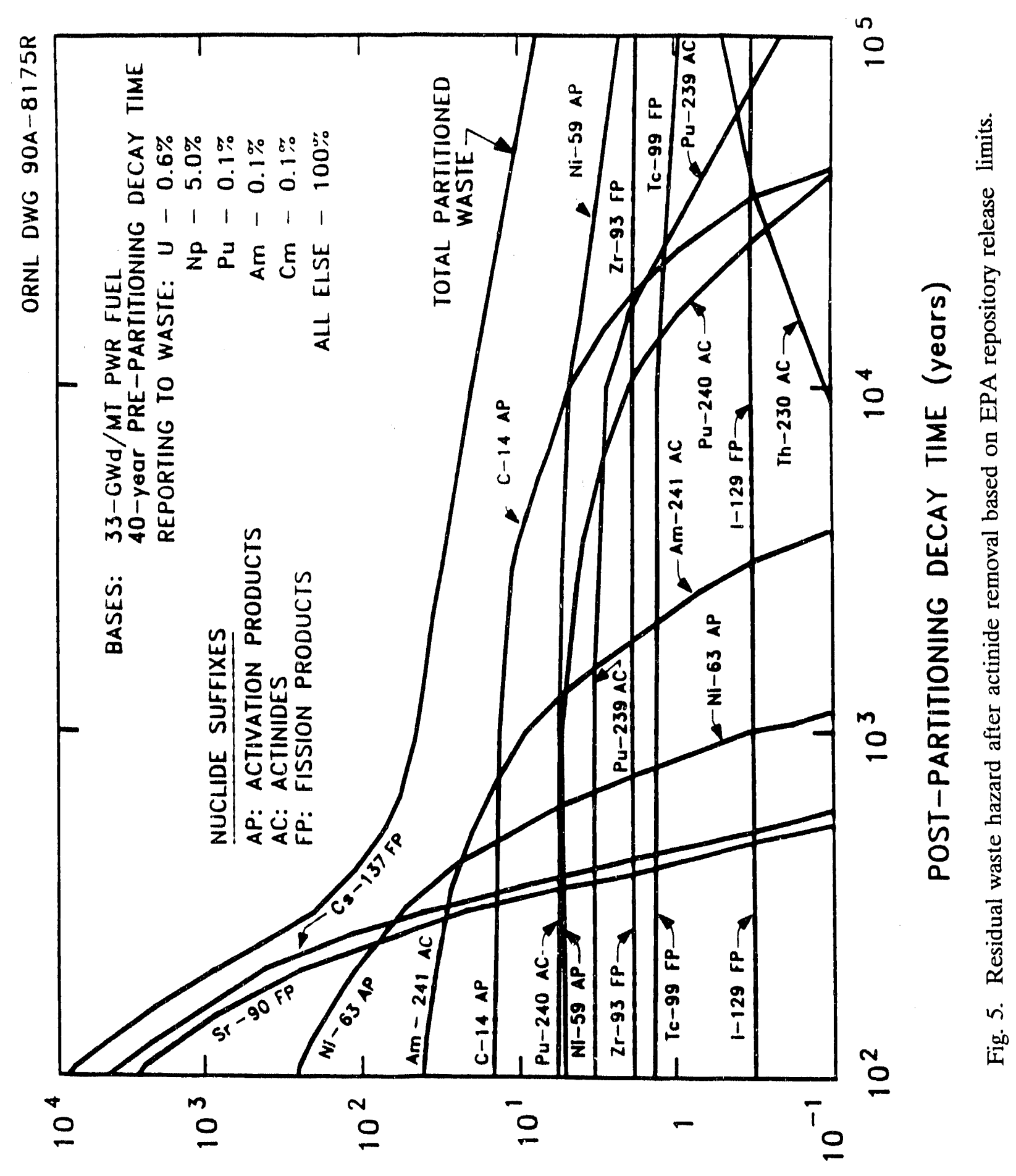

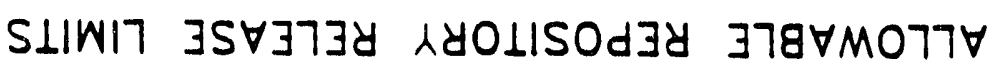

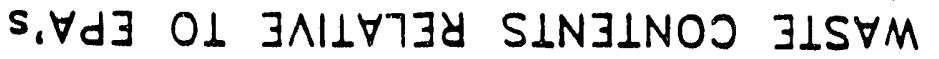


There is a time dimension to radioactive waste management. Radioactivity is an instantaneous measure of hazard. The scales, based on air and water, integrate risk or hazard from a particular radionuclide pathway to man over the lifetime of an individual. Both scales have built into them the idea that a person can ingest water and breath air over a lifetime without significant health risk if radionuclide concentrations in air and water are below these standards. Although the repository standard is more complex, it is a multigenerational standard, considering HEs over a period of 10,000 years and multiple generations.

There is a population (community) dimension to waste management. Air and water standards are designed to protect individuals and limit their lifetime risk, below some defined level. They were not designed to consider low-radiation exposures to large numbers of individuals. The EPA standard is a community (population) standard, having been written to limit total health impact to the community over time. Its derivation considered the possible impact of relatively small radiation doses to very large numbers of people. It is this consideration that leads to the regulatory format of limits on cumulative releases over 10,000 years rather than yearly relcase limits.

Last, repositories have multiple failure modes. The first three scales have limited applicability in defining repository risk because each focuses on measuring hazard in a single dimension. The EPA standard is stronger because it addresses multiple possible modes of repository failure and release of radionuclides to the environment. At the same time, it has a limitation. It is a regulatory standard to define maximum allowable releases to the environment for any repository. The development of the standard made no assumption about which repository failure modes dominate. The radionuclides of concern are identical for many repository failure modes, which makes the standard stronger; however, the standard may underestimate the real risks from those radionuclides that would be released if the repository operated exactly as expected $\left({ }^{129} \mathrm{I},{ }^{99} \mathrm{Tc},{ }^{237} \mathrm{~Np}\right)$.

\subsection{ANALYSIS}

For waste management purposes, including actinide burning, the EPA standard for waste management is the preferred surrogate measure of risk because:

(1.) It is the only surrogate measure designed for waste management, and its derivation explicitly accounts for the specific unique issues in waste management: 
- very long time frames (10,000 years and beyond),

- community (versus individual) radiation exposures, and

- $\quad$ multiple (versus single) repository failure modes.

(2.) It is the legal standard of acceptable repository risk. If the hazard of the waste is reduced, the legal requirements for the performance of the repository are reduced and repository licensing is simplified, it will be easier to demonstrate regulatory compliance.

This surrogate measure of risk is not preferred in relation to a comprehensive risk assessment, which is the ultimate measure of repository performance. 


\section{POTENTIAL IMPACTS OF AC INIDE BURNING ON REPOSITORY RISK}

This section will evaluate the potential impacts that actinide burning (i.e., removal of actinides from repository wastes) will have on post-closure repository risk. Additionally, other long-term repository-related benefits will be considered in this section. These impacts will be considered in the context of the issues identified in Sect. 2.6, Item 3.

For the purposes of this analysis, it will be assumed that $0.1 \%$ of the actinides originally in the SF report to the repository as waste. At this point, the toxicity of the nonactinide components of SF are more significant than the actinides (sce Sect. 3).

\subsection{ACTINIDE BURNING MAY REDUCE UNCERTAINTY IN LONG-TERM RISK}

Actinide burning removes and destroys selected long-lived radionuclides decreasing repository risk by reduction of the source term (S). When technically and economically feasible, reduction of source term is the preferred waste management option over other disposal options because it eliminates long-term risks. What does not exist cannot create risk or uncertainty. This has been the basis of general EPA policies [RITTMEYER 1991]. This reduction is independent of repository characteristics $(\mathrm{P}, \mathrm{E}, \mathrm{M})$.

The degree to which uncertainty is reduced depends on the importance of the actinides as a determinant of uncertainty. If it is assumed that the upper boundary of uncertainty is defined by the maximum potential consequences that might result from a repository release, then actinide burning can reduce this uncertainty by about a factor of 1000 (Fig. 4). This occurs because the actinides are the most toxic long-lived component of the SF and, thus, define the maximum consequences of a release. Reduction of uncertainty is proportional to reduction in actinide inventory up to the point where the nonactinides dominate, which is approximately a factor of 1000 for times after disposal between $10^{3}$ and $10^{5}$ years.

Despite the reduction in uncertainty, actinide removal per se is not expected to significantly decrease the SLAM scenario risk when currently expected reference conditions are employed. The small volumes of water and low actinide solubility would effectively contain the actinides within the repository under these conditions. Risk under expected conditions may be reduced by either removing and transmuting radionuclides, such as ${ }^{99} \mathrm{Tc}$ and ${ }^{129} \mathrm{I}$, or by placing them in a special leach-resistant matrix. 


\subsection{ACTINIDE BURNING MAY PRODUCE IMPROVED WASTE FORMS THAT HAVE LOWER RELEASE RATES}

The current waste form for the U.S. repository is SF. Actinide burning implies reprocessing and the option of choosing the waste form to optimize waste performance [PIGFORD 1990a, PIGFORD 1990b, MEANS 1987]. This can reduce the escape fraction (E) of radionuclides for many repository failure modes by orders of magnitude. This improvement in repository performance reduces the risk of release for all radionuclides in the repository, not just actinides. Improved waste forms reduce escape fractions by several mechanisms:

(1.) For most tepositories, the water leach failure mode (SLAM) is the dominant contributor to risk. A key step in the SLAM scenario is dissolution of the waste. With less soluble waste forms, the waste dissolution rate is much lower.

(2.) Waste forms can be chosen to avoid creation of small particles, which reduces potential releases of radioactivity by transport of colloids.

(3.) For expulsive events, high-integrity waste forms imply fewer fine particles with less transport in the environment.

Better waste forms is a potential advantage of actinide burning; but, it is also possible to gain these advantages by other waste processing technologies. There are multiple mechanisrris by which improved waste-form performance is obtained.

(1.) The geometric form of HLW is superior to that of SF. Nuclear fuel has a high surface-to-volume ratio to maximize heat transfer in the reactor from nuclear fuel to reactor coolant. Furthermore, some fission products will have escaped the fuel matrix and concentrated in the gap between fuel pellets and clad [PIGFORD 1990a]. The high surface-to-volume ratio SF maximizes mass transfer of radionuclides to the groundwater and, hence, to the environment. In comparison, HLW has a low surface-to-volume ratio.

(2.) HLW (borosilicate glass or an equivalent from pyrochemical processing) is chemically more compatible in chemically oxidizing environments, such as exist at the proposed Yucca Mountain repository, than is SF and has a lower dissolution rate than SF in water. With any waste form, radionuclides are embedded in a matrix material. If the matrix material is slow to dissolve or 
disintegrate (congruent dissolution), release of radionuclides will be slow. In an oxidizing environment, the $\mathrm{UO}_{2}$ in light-water reactor SF converts to $\mathrm{U}_{3} \mathrm{O}_{8}$ [APTED 1990, EINZIGER 1991, RAMSPOTT 1992, LUTZE 1988], which is a lower-density form of uranium. This slow chemical conversion disintegrates the $\mathrm{UO}_{2}$ (which encapsulates most of the fission products and actinides) into a fine powder, which allows easier release of various radionuclides to air or water [WILSON 1989, WiLSON 1990]. HLW, in comparison, provides a relatively high integrity waste form [STRACHAN 1990]. All of the currently proposed HLW forms contain silica. Almost all types of groundwater are saturated in silica. Experiments in water leaching of various waste forms show the radionuclide leach rate dropping rapidly with time because of the formation of a radionuclide-depleted silica layer around each HLW piece or particle [NAS 1983]. This acts as a barrier against further radionuclide release. (Note: in repositories with chemically reducing environments, SF is stable against chemical attack.)

(3.) HLW is a more concentrated waste form with the waste per unit of electricity produced in fewer packages. For very low solubility radionuclides, the release rate of radionuclides from the waste is proportional to water flow by the waste [HIRSCHFELDER, 1991]. The higher the concentrations of radionuclides in the waste, the more water (and more time) before any fixed fraction of the radionuclides are released from the waste.

\subsection{ACTINIDE BURNING MAY ALLOW FOR IMPROVED MANAGEMENT OF TROUBLESOME NONACTINIDES}

The reprocessing of SF that is an inherent part of actinide burning allows for improved management of troublesome nonactinides (i.e., soluble, nonabsorbed, or both) in two ways. First, for certain troublesome radionuclides $\left({ }^{14} \mathrm{C},{ }^{99} \mathrm{Tc},{ }^{135} \mathrm{Cs}\right.$, and $\left.{ }^{129} \mathrm{I}\right)$, specific chemical compounds can be used as waste forms with very low water solubility [NAS 1983]. The improvements possible in waste performance are a function of the chemistry of the radionuclide. For some radionuclides, such as ${ }^{129} \mathrm{I}$, waste performance (leach rate) can be 
improved by as much as five orders of magnitude [PIGFORD 1990b]. For other radionuclides, the gains are less [PIGFORD 1990a, NAS 1983] but still significant (Table 2).

Second, some of the troublesome non-actinides are made available through reprocessing for iransmutation. In particular, ${ }^{99} \mathrm{Tc}$ and ${ }^{129} \mathrm{I}$ can be separated from the waste streams and transmuted to essentially non-toxic species. These nuclides typically dominate the risks from the SLAM scenario [PIGFORD 1990b, LOGAN 1980, APTED 1990, NAS 1983], and their destruction may significantly reduce repository risk (by eliminating the dominant expected contributors) and uncertainty (by eliminating significant components of the inventory).

\subsection{ACTINIDE BURNING MAY GREATLY REDUCE THE POTENTIAL ADVERSE IMPACTS OF COLLOIDS AND COMPLEXES}

By definition, actinide burning results in essentially no actinides reporting to the repository. As a result, the colloids and complexes that might form with the actinides and transport them to the biosphere more rapidly simply cannot exist. This is another manifestation of the approach stated in Sect. 4.1: What does not exist cannot create risk or uncertainty.

\subsection{ACTINIDE BURNING MAY REDUCE THE RISK FROM POTENTIAL ADVERSE HYDROLOGIC CONDITIONS}

Two different types of adverse hydrologic conditions might occur at a potential repository site such as Yucca Mountain. The first is substantially increased water infiltration rates. Such an increase could be produced by changes in surface activities, changes in subsurface water flow patterns, or increased precipitation resulting from climatic changes. In this case, the increased volume of water allows more actinides (which are solubility limited) to be dissolved and transported to the biosphere.

The second kind of adverse hydrologic condition is one in which the subsurface water flow rate is significantly increased. This might occur because of greater-than-expected amounts of water flow through fractures (as opposed to the rock matrix) or hydrologic "short circuits" caused by human intrusion or seismic activity. A decrease in the time it takes radionuclide-bearing water to reach the biosphere means that nuclides that would have been 
Table 2. Potential improvements in waste isolation by use of high-performance, special waste forms compared to typical HLW glass waste form.

\begin{tabular}{ccc}
\hline Isotope & $\begin{array}{c}\text { Improvement } \\
\text { factor }\end{array}$ & Waste form \\
\hline${ }^{14} \mathrm{C}$ & 500 & $\mathrm{CaCO}_{3}$ \\
${ }^{129} \mathrm{I}$ & $8 \times 10^{5}$ & $\mathrm{AgI}$ \\
${ }^{135} \mathrm{Cs}$ & $10^{4}$ & SYNROC \\
\hline
\end{tabular}

1. Ref. [NAS 1983], p. 269.

2. Improvements compared to HLW with congruent dissolution in repository. For ${ }^{14} \mathrm{C}$ and ${ }^{129} \mathrm{I}$, assume special waste form with only named radionuclide in high concentration. For ${ }^{135} \mathrm{Cs}$, assume cesium with other radionuclides. Improvements would be greater compared to SF. 
expected to be retarded to the point that they would decay during migration now reach the biosphere, impacting humans.

Actinide burning may reduce the risk from this effect by (a) eliminating many of the nuclides from the repository inventory so that they cannot impact humans, and (b) producing superior waste forms that limit the solubilization of radionuclides.

\subsection{ACTINIDE BURNING MAY REDUCE THE RISK FROM THE EXPULSIVE RELEASE SCENARIO}

According to available information, the actinides dominate the consequences of the expulsive release scenario by about a factor of 100 . Removal of the actinides during reprocessing will reduce the consequences from this scenario by the same factor.

The extent to which this reduces the overall risk depends heavily on the probability of the expulsive event. The value used by LOGAN [1980], which was an expected expulsive event every 100 billion years, should be considered to be a minimum because the bedded salt assumed in that study is found in regions of low tectonic activity. The probability of such an event at the Yucca Mountain site will almost certainly be much greater than this because of the volcanic origins of the site and higher regional seismicity.

\subsection{ACTINIDE BURNING MAY REDUCE THE RISKS FROM HUMAN INTRUSION}

The risks from human intrusion are reduced because:

(1.) the actinides that dominate the consequences from material brought to the surface are reduced by a factor of 1000 ,

(2.) the improved waste form leachability reduces the adverse effects of a hydrologic "short circuit" that may be caused by drilling.

(3.) the waste in the repository has essentially no fissile material, and other valuable metals can also be removed during reprocessing. This effectively eliminates the motive for a deliberate intruder to penetrate the repository to mine valuable constituents of the SF. 


\subsection{ACTINIDE BURNING MAY DECREASE RELIANCE ON LONG-TERM PREDICTION OF ENGINEERED BARRIER PERFORMANCE}

Actinide burning removes a major portion, if not essentially all, of the significant longlived constituents of SF for alternative disposition. As a result, the HLW is relatively shortlived and decays to inconsequential levels much more quickly. In particular, the HLW is just 20 to 40 times the EPA release limits at a decay time of 1000 years, based on inventory considerations alone. The SF is nearly 1000 times this value. As a result of the lower inventories of hazardous materials, the performance level that might be required of the engineered barrier system beyond 1000 years is substantially reduced. This may justify reevaluation of NRC waste package requirements based on the reduced toxicity of the waste.

\subsection{ACTINIDE BURNING MAY FACILITATE SHOWING COMPLIANCE WTTII REGULATIONS}

The potential reductions in risk and uncertainty listed previously should make providing reasonable assurance of compliance with applicable regulations, especially the EPA standard, much easier. The most graphic example of this is Fig. 4, in which it is shown that radionuclide inventory reduction alone will result in about a thousand-fold reduction in the extent to which the repository inventory exceeds the release limits. Other benefits of actinide burning (e.g., the improved waste form, potential elimination of soluble radionuclides that dominate the SLAM scenario) are expected to be equally important but cannot be easily quantified. 


\section{CONCLUSIONS}

(1.) The most widely accepted measure of repository performance is risk (probability times consequences) as determined by a comprehensive PRA.

1.1 The PRA should account for:

- $\quad$ the SLAM scenario, including potential adverse factors such as climatic change, colloids, and complexing agents;

- low-probability, high-consequence expulsive events such as volcanoes; and

- deliberate and inadvertent human intrusion.

1.2 A comprehensive PRA requires an extensive data base and is both complex and time-consuming.

(2.) Existing performance analyses indicate that the risk from the repository is small compared with other generally accepted risks by society and the rest of the nuclear fuel cycle, but such analyses are not available for the Yucca Mountain candidate repository site.

(3.) Actinide removal per se is not expected to significantly reduce the risk from the SLAM scenario under currently expected reference conditions.

(4.) Easily calculable surrogate measures of risk are available, but all of them have significant limitations, as compared with a comprehensive PRA.

4.1 Short of a comprehensive PRA, a surrogate measure that expresses risk in terms of multiples of the cumulative repository release limits given in the EPA standard 40 CFR 191 is preferred over other surrogate measures.

(5.) Actinide burning (i.c., removal of actinides from repository wastes) may provide a number of long-term risk-related benefits to the repository:

5.1 Removal of the actinides may reduce the uncertainty in long-term risk by reducing the maximum consequences from a varicty of release scenarios (expulsive events, human intrusion) by about a factor of 1000 from $10^{3}$ to $10^{5}$ years after disposal.

5.2 Actinide burning may eliminate the potential adverse effects of actinide transport by colloids or complexes because the actinides are not in the repository. 
5.3 Actinide burning reduces risk from the expulsive release scenario by about a factor of 100 based on results from existing studies (not specific to the Yucca Mountain site).

5.4 Actinide burning may reduce the risks from human intrusion by (a) reducing the consequences from waste material brought to the surface by a factor of 1000 , and (b) reducing the probability of deliberate intrusion by eliminating the plutonium that may provide the impetus for doing so.

5.5 Actinide burning may reduce the risk from potential adverse hydrologic factors by eliminating many nuclides from the repository inventory so that they cannot be transported to the biosphere.

5.6 Actinide burning may decrease reliance on long-term predictions of engineered barrier performance by greatly reducing the effective life of the waste and providing a basis for reducing the required containment time from 1000 to 300 years.

(6.) Actinide burning requires processing of SF. The processing of spent fuel may provide a number of other long-term risk-related benefits to the repository compared to direct SF disposal.

6.1 Actinide burning allows selection of a waste form (borosilicate glass or equivalent) that may not degrade under oxidizing repository conditions such as expected at the candidate Yucca Mountain site. With these conditions, glass has a much lower release rate for all radionuclides contained in it compared with SF. This reduces risk from the SLAM scenario and other scenarios for all radionuclides.

6.2 Actinide burning may allow for improved management of troublesome nonactinides (e.g., ${ }^{14} \mathrm{C},{ }^{99} \mathrm{Tc}$, and ${ }^{129} \mathrm{I}$ ) by either incorporating them into improved waste forms or making them available for transmutation.

(7.) Actinide burning may facilitate licensing by reducing risk and uncertainty, which should make demonstrating compliance with applicable regulations easier. 


\section{REFERENCES}

AHN 1992

APTED 1990

BROWN 1982

CHANNELL 1991

CLAIBORNE 1974

CROFF 1980

CROFF 1990

EINZIGER 1991

EPA 1982a
J. Ahn and S. Nakayama, "Modelling for Mitigation of a Redox-Sensitive Radionuclide in Engineered Barriers," Nucl. Technol 97,323 (March 1992).

M. J. Apted, W. J. O'Connell, K. H. Lee, A. T. MacIntyre, T. S. Ueng, T. H. Pigford, and W. W. Lee, Preliminary Calculations of Release Rates of ${ }^{99} \mathrm{Tc},{ }^{129} \mathrm{I},{ }^{135} \mathrm{Cs}$, and ${ }^{237} \mathrm{~Np}$ From Spent Fuel in a Tuff Repository, Working Group 2: The Engineered Barrier System Group, Office of Civilian Radioactive Waste Management, WG2-5-90 (1990).

M. I. Brown and E. Crouch, Extreme Scenarios for Nuclear Waste Repositories, Health Physics 43, (3), 345 (1982).

J. K. Channell, L. Chaturvedi, R. H. Neill, "Human Intrusion Scenarios in Nuclear Waste Repository Evaluations," Proc. Second Int. Conf. High-Level Radioactive Waste Management, Am. Nucl. Soc., Las Vegas, Nevada (1991).

H. C. Claiborne and F. Gera, Potential Containment Failure Mechanisms and Their Consequences at a Radioactive Waste Repository In Bedded Salt in New Mexico, ORNL-TM-4639 (1974).

A. G. Croff, Origen 2: A Revised and Updated Version of the Origen Computer Code, ORNL-5621 (1980).

A. G. Croff, C. W. Forsberg, and S. B. Ludwig, "A Recxamination of the Incentives for Actinide Burning," Trans. Am. Nucl. Soc., Washington, D.C. (1990).

R. E. Einziger, S. C. Marschman, and H. C. Buchanan, "Spent Fucl Dry-Bath Oxidation Testing," Nucl. Tech. 94, 3, 383, (1991).

U.S. Environmental Protection Agency, Draft Environmental Impact Statement for 40 CFR 191: Environmental Standards for Management and Disposal of Spent Nuclear Fuel, HighLevel and Transuranic Radioactive Wastes, EPA 520/1-82-025 (1982). 
EPA $1982 b$

EPA 1985a

EPA $1985 b$

EPA $1985 c$

FORSBERG 1991

GOTCHY 1987

HILL 1980

HIRSCHFELDER 1991

HUNTER 1986

HONENEMSER 1990
U.S. Environmental Protection Agency, Population Risks from Disposal of High-Level Radioactive Wastes in Geological Repositories, EPA/520/3 80-006 (Dec. 1982).

U.S. Environmental Protection Agency, 1985a, Background Information Document Final Rule for High-Level and Transuranic Radioactive Waste, EPA 520/1-85-023 (1985).

U.S. Environmental Protection Agency, 1985b, High-Level and Transuranic Radioactive Wastes: Responses to Comments for Final Rule, Vol. 1, EPA 520/1-85-024-1 (1985).

U. S. Environmental Protection Agency, Title 40, Part 191, "Environmental Standards for the Management and Disposal of Spent Nuclear Fuel, High-Level and Transuranic Radioactive Wastes," FEDERAL REGISTER 50, 38066 (September 19, 1985).

C. W. Forsberg, Representative Geological Repository Designs for Spent Fuel and High-Level Waste, K/ITP-393 (1991).

R. L. Gotchy, Potential Health and Environmental Impacts Attributable to the Nuclear and Coal Fuel Cycles, NUREG0332, U.S. Nuclear Regulatory Commission.

M. D. Hill, I. F. White, A. B. Fleishman, The Effects of Actinide Separation on the Radiological Consequences of Geological Disposal of High-Level Waste, National Radiation Protection Board, Great Britain, NRPB-R95 (1980).

J. Hirschfelder, P. L. Cambré, W. W. Lee, T. H. Pigford, and M. M. Sadeghi, "Effects of Actinide Burning on Waste Disposal at Yucca Mountain," Trans. Am. Nucl. Soc., San Francisco, 64:111 (November 10-14, 1991).

R. L. Hunter, R. M. Cranwell, and M. S. Y. Chu, Assessing Compliance with the EPA High-Level Waste Standard: An Overview, Sandia National Laboratories, NUREG/CR-4510, SAND86-0121.

C. Honenemser, R. L. Goble, and P. Slovic, "Institutional Aspects of Future Developments of Nuclear Power," Annu. Rev. Energy, 15:173 (1990). 
ICRP 1979

KOLLURU 1991

LINK 1982

LOGAN 1980

LUTZE 1988

MEANS 1987

NAS 1983

NAS 1990a

NAS $1990 b$

NEA 1989

NRC 1986

NRC 1975a
International Commission on Radiation Protection, 1979, "Limits for Uptakes of Radionuclides by Workers," Ann. ICRP, 2, 3/4, ICRP Publication 30 (1979).

R. V. Kolluru, "Understanding the Basics of Risk Assessment," Chemical Engineering Progress, p. 61 (1991).

R. L. Link et al., Parametric Studies of Radiological Consequences of Basaltic Volcanism, Sandia National Laboratories, SAND81-2375 (1982).

S. E. Logan et al., Actinide Partitioning-Transmutation Program Final Report: VII Long-term Risk Analysis of the Geological Repository, Oak Ridge National Laboratory, ORNL/TM-6987 (1980).

W. Lutze and R. C. Ewing, Radioactive Waste Forms for the Future, North-Holland, Amsterdam

J. L. Means, A. J. Markworth, and J. K. McCoy, Long-Term Performances of Spent Fuel Waste Forms, NUREG/CR-4954, U.S. Nuclear Regulatory Commission (1987).

National Academy of Sciences, 1983, A Study of the Isolation System for Geological Disposal of Radioactive Wastes, National Academy Press, Washington, D.C. (1983).

National Academy of Science, National Research Council, 1990a, Rethinking High-Level Radioactive Waste Disposal, National Academy Press, Washington, D.C. (1990).

National Academy of Science, Proc. of the Symposium on Radioactive Waste Repository Licensing, Washington, D.C. (In Press).

Nuclear Energy Agency, Risks Associated with Human Intrusion at Radioactive Waste Disposal Sites, Paris (June 5-7, 1989).

U. S. Nuclear Regulatory Commission, Title 10, Part 60, "Disposal of High-Level Radioactive Wastes in Geologic Repositories," FEDERAL REGISTER 51, 27162 (July 30, 1986).

Nuclear Regulatory Commission, 20, Code of Federal Regulations, 10CFR20. 
NRC 1975b

NUTTALL 1991

PIGFORD 1990a

PIGFORD 1990b

POSTON 1978

RAMSPOTT 1992

RITTMEYER 1991

ROWE 1977

SAKERHET 1978

SMITH 1980

STRACHAN 1990

VOSS 1979
U. S. Nuclear Regulatory Commission, Title 10 Part 20 "Standards for Protection Against Radiation," FEDERAL REGISTER 40, 50705 (October 31, 1975).

H. E. Nuttall, R. Jain, and Y. Fertelli, "Radiocolloid Transport in Saturated and Unsaturated Fractures," Proc. of the Second Int. Conf. High-Level Radioactive Waste Management, Am. Nuc. Soc., Las Vegas, Nevada, (1991).

T. H. Pigford, "Reprocessing Incentives for Waste Disposal," Trans. Am. Nuc. Soc., 62:97 (1990).

T. H. Pigford, Actinide Burning and Waste Disposal, UCBNE-4176 (Oct. 5, 1990).

J. W. Poston, Measures of Equivalent Hazard of Radionuclides: A Survey, Y/OWI/SUB-7278/2 (1978).

L. D. Ramspott, J. Choi, W. Halsey, A. Pasternak, T. Cotton, J. Burns, A. McCabe, W. Colglazier, and 'N. Lee, Impacts of New Developments in Partitioning and Transmutation on the Disposal of High-Level Nuclear Waste in a Mined Gcological Repository, UCRL ID-109203 (March 1992).

R. W. Rittmeyer, "Prepare an Effective Pollution-Prevention Program," Chemical Engineering Progress 87:5, 56 (1991).

W. D. Rowe, An Anatomy of Risk, John Wiley \& Sons (1977).

Kärn Bränsle Säkerhet, Handling and Final Storage of Unreprocessed Spent Nuclear Fuel, Stockholm, Sweden (1978).

C. F. Smith, J. J. Cohen, T. E. Mckone, A Hazard Index for Underground Toxic Material, Lawrence Livermore Laboratory, UCRL-52889 (1980).

D. M. Strachan, B. P. McGrail, M. J. Apted, D. W. Engel, and P. W. Eslinger, Preliminary Assessment of the Controlled Release of Radionuclides from Waste Packages Containing Borosilicate Waste Glass, PNL-7591 (June 1990).

J. W. Voss, Safety Indices and Their Application to Nuclear Waste Management Safety Assessment, Pacific Northwest Laboratory, PNL-2727 (1979). 
WILSON 1989

C. N. Wilson, C. J. Bruton, Studies on Spent Fuel Dissolution Behavior Under Yucca Mountain Repository Conditions, PNL-SA-16832 (July 1989).

WILSON 1990

C. N. Wilson, Results from NNWSI Series 3 Spent Fuel Dissolution Tests, PNL-7170 (June 1990). 


\section{APPENDIX A: NUMERICAL SURROGATE MEASURES OF RISK}

Chapter 3 discussed surrogate measures of risk. This appendix provides the numerical values generated in calculating these measures of risk. These tables list all radionuclides which create $1 \%$ or more of the risk using any of the four surrogate measures of repository risk. 
Table A.1 Radioactivity (curies) of one metric ton of pressurized water reactor spent fuel versus time

Time (years)

\begin{tabular}{|c|c|c|c|c|c|c|}
\hline & & & e yea & & & \\
\hline Isotopes & $1.0 \mathrm{e}+1$ & $1.0 \mathrm{e}+2$ & $1.0 \mathrm{e}+3$ & $1.0 \mathrm{e}+4$ & $1.0 \mathrm{e}+5$ & $1.0 c+6$ \\
\hline
\end{tabular}

Activation Products

\begin{tabular}{|c|c|c|c|c|c|c|}
\hline $\mathrm{H}-3$ & $1.5 \mathrm{e}-02$ & 0.96 & $1.1 \mathrm{e}-22$ & 0 & 0 & 0 \\
\hline CL-14 & 1.5 & 1.4 & 1.3 & 0.44 & $8.1 e-06$ & 0 \\
\hline CL-36 & 0.011 & 0.011 & 0.011 & 0.011 & 0.0091 & 0.0011 \\
\hline FE-55 & $3.7 e+02$ & $1.4 \mathrm{e}-08$ & 0 & 0 & 0 & 0 \\
\hline CO-60 & $3.1 e+03$ & 0.023 & 0 & 0 & 0 & 0 \\
\hline NI-59 & 3.9 & 3.9 & 3.9 & 3.6 & 1.6 & 0.00067 \\
\hline NI-63 & $6.1 e+02$ & $3.1 \mathrm{c}+02$ & 0.35 & $1.2 \mathrm{e}-30$ & 0 & 0 \\
\hline ZR-93 & 0.26 & 0.26 & 0.26 & 0.26 & 0.25 & 0.17 \\
\hline NB-93M & 0.11 & 0.25 & 0.25 & 0.25 & 0.24 & 0.16 \\
\hline NB-94 & 1.3 & 1.3 & 1.3 & 0.92 & 0.043 & $1.9 c-15$ \\
\hline MO-93 & 0.024 & 0.024 & 0.02 & 0.0033 & $6.0 e-11$ & 0 \\
\hline SB-125 & $1.2 \mathrm{e}+02$ & $2.0 \mathrm{e}-08$ & 0 & 0 & 0 & 0 \\
\hline SUMTOT & $4.4 \mathrm{e}+03$ & $3.2 e+02$ & 7.3 & 5.4 & 2.2 & 0.32 \\
\hline TOTAL & $4.4 e+03$ & $3.2 c+02$ & 7.3 & 5.4 & 2.2 & 0.32 \\
\hline \multicolumn{7}{|l|}{ Actinides } \\
\hline PB-209 & $1.2 \mathrm{e}-07$ & $9.6 \mathrm{e}-07$ & 0.00013 & 0.017 & 0.39 & 0.94 \\
\hline PB-210 & $4.5 \mathrm{e}-08$ & 0.000014 & 0.0031 & 0.13 & 1.1 & 0.46 \\
\hline PB-214 & $3.6 \mathrm{e}-07$ & 0.000026 & 0.0031 & 0.13 & 1.1 & 0.46 \\
\hline BI-210 & $4.5 e-08$ & 0.000014 & 0.0031 & 0.13 & 1.1 & 0.46 \\
\hline BI-213 & $1.2 \mathrm{e}-07$ & $9.6 \mathrm{e}-07$ & 0.00013 & 0.017 & 0.39 & 0.94 \\
\hline BI-214 & $3.6 \mathrm{c}-07$ & 0.000026 & 0.0031 & 0.13 & 1.1 & 0.46 \\
\hline PO-210 & $4.5 e-08$ & 0.000014 & 0.0031 & 0.13 & 1.1 & 0.46 \\
\hline PO- 213 & $1.2 \mathrm{e}-07$ & $9.4 \mathrm{e}-07$ & 0.00013 & 0.017 & 0.38 & 0.92 \\
\hline PO-214 & $3.6 c-07$ & 0.000026 & 0.0031 & 0.13 & 1.1 & 0.46 \\
\hline PO-218 & $3.6 e-07$ & 0.000026 & 0.0031 & 0.13 & 1.1 & 0.46 \\
\hline AT-217 & $1.2 \mathrm{e}-07$ & $9.6 \mathrm{e}-07$ & 0.00013 & 0.017 & 0.39 & 0.94 \\
\hline RN-219 & $5.0 \mathrm{e}-06$ & 0.000039 & 0.00036 & 0.0034 & 0.022 & 0.028 \\
\hline RN-222 & $3.6 \mathrm{e}-07$ & 0.000026 & 0.0031 & 0.13 & 1.1 & 0.46 \\
\hline FR-221 & $1.2 \mathrm{e}-07$ & $9.6 e-07$ & 0.00013 & 0.017 & 0.39 & 0.94 \\
\hline RA-225 & $1.2 \mathrm{e}-07$ & $9.6 \mathrm{e}-07$ & 0.00013 & 0.017 & 0.39 & 0.94 \\
\hline RA-226 & $3.6 \mathrm{e}-07$ & 0.000026 & 0.0031 & 0.13 & 1.1 & 0.46 \\
\hline AC- -225 & $1.2 \mathrm{e}-07$ & $9.6 c-07$ & 0.00013 & 0.017 & 0.39 & 0.94 \\
\hline TH-229 & $1.2 \mathrm{e}-07$ & $9.6 \mathrm{e}-07$ & 0.00013 & 0.017 & 0.39 & 0.94 \\
\hline TH-230 & 0.00013 & 0.0013 & 0.017 & 0.17 & 1.1 & 0.46 \\
\hline TH-234 & 0.32 & 0.32 & 0.32 & 0.32 & 0.32 & 0.32 \\
\hline PA-233 & 0.34 & 0.44 & 1 & 1.2 & 1.2 & 0.89 \\
\hline PA-234M & 0.32 & 0.32 & 0.32 & 0.32 & 0.32 & 0.32 \\
\hline U-233 & 0.000027 & 0.00018 & 0.0034 & 0.05 & 0.42 & 0.94 \\
\hline U-234 & 1.2 & 1.6 & 2 & 2 & 1.6 & 0.42 \\
\hline U-236 & 0.26 & 0.26 & 0.27 & 0.35 & 0.39 & 0.38 \\
\hline
\end{tabular}


Table A.1. Radioactivity (curies) of one metric ton of pressurized water reactor spent fucl versus time (continued)

Time (years)

\begin{tabular}{|c|c|c|c|c|c|c|}
\hline \multirow{2}{*}{ Isotopes } & \multirow[b]{2}{*}{$1.0 \mathrm{e}+1$} & \multirow{2}{*}{$1.0 c+2$} & & \multirow[b]{2}{*}{$1.0 \mathrm{c}+5$} & \multirow[b]{2}{*}{$1.0 e+6$} \\
\hline & & & $1.0 \mathrm{e}+3$ & $1.0 \mathrm{c}+4$ & & \\
\hline U-238 & 0.32 & 0.32 & 0.32 & 0.32 & 0.32 & 0.32 \\
\hline NP-237 & 0.34 & 0.44 & 1 & 1.2 & 1.2 & 0.89 \\
\hline NP-239 & 18 & 18 & 17 & 7.1 & 0.0015 & $8.4 c-08$ \\
\hline PU-238 & $2.4 \mathrm{c}+0.3$ & $1.2 \mathrm{e}+0.3$ & 1.3 & $4.7 c-19$ & 0 & 0 \\
\hline PU-239 & $3.3 c+02$ & $3.3 c+02$ & $3.2 c+02$ & $2.5 e+02$ & 19 & $8.4 \mathrm{e}-08$ \\
\hline PU-240 & $4.8 c+02$ & $4.8 c+02$ & $4.4 c+02$ & $1.7 e+02$ & 0.012 & $4.6 c-107$ \\
\hline PU-241 & $7.9 e+04$ & $1.0 \mathrm{e}+03$ & 0.15 & 0.071 & 0.000046 & $6.1 \mathrm{e}-37$ \\
\hline PU-242 & 1.8 & 1.8 & 1.8 & 1.7 & 1.5 & 0.29 \\
\hline AM-241 & $1.7 c+03$ & $3.8 c+0.3$ & $9.1 e+02$ & 0.071 & 0.000046 & $6.4 c-37$ \\
\hline AM-243 & 18 & 18 & 17 & 7.1 & 0.0015 & $8.4 \mathrm{e}-08$ \\
\hline CM-244 & $1.5 c+03$ & 47 & $52 \mathrm{c}-14$ & 0 & 0 & 0 \\
\hline SUMTOT & $8.6 c+04$ & $7.0 e+03$ & $1.7 e+03$ & $4.4 c+02$ & 40 & 17 \\
\hline TOTAL & $8.6 c+04$ & $7.0 \mathrm{e}+03$ & $1.7 \mathrm{e}+03$ & $4.4 c+02$ & 40 & 17 \\
\hline \multicolumn{7}{|c|}{ Fission products } \\
\hline SE-79 & 0.41 & 0.41 & 0.4 & 0.37 & 0.14 & $9.5 e-06$ \\
\hline KR-85 & $4.9 c+03$ & 14 & $7.7 e-25$ & 0 & 0 & 0 \\
\hline SR-90 & $5.7 e+04$ & $6.7 c+03$ & $3.4 c-06$ & 0 & 0 & 0 \\
\hline Y-90 & $5.8 c+04$ & $6.8 c+0.3$ & $3.4 \mathrm{e}-06$ & 0 & 0 & 0 \\
\hline ZR-93 & 1.8 & 1.8 & 1.8 & 1.8 & 1.7 & 1.2 \\
\hline NB-93M & 0.77 & 1.7 & 1.7 & 1.7 & 1.6 & 1.1 \\
\hline TC-99 & 1.3 & 13 & 13 & 13 & 9.5 & 0.51 \\
\hline PD-107 & 0.11 & 0.11 & 0.11 & 0.11 & 0.11 & 0.1 \\
\hline SN-126 & 0.76 & 0.76 & 0.75 & 0.71 & 0.38 & 0.00074 \\
\hline SB-126 & 0.11 & 0.11 & 0.11 & 0.099 & 0.053 & 0.0001 \\
\hline SB-126M & 0.76 & 0.76 & 0.75 & 0.71 & 0.38 & 0.00074 \\
\hline I-129 & 0.031 & 0.031 & 0.031 & 0.031 & 0.031 & 0.03 \\
\hline CS-134 & $5.5 c+0.3$ & $4.0 c-10$ & 0 & 0 & 0 & 0 \\
\hline CS-135 & 0.36 & 0.36 & 0.36 & 0.36 & 0.35 & 0.27 \\
\hline CS-137 & $8.2 c+04$ & $1.0 \mathrm{c}+04$ & $9.6 c-06$ & 0 & 0 & 0 \\
\hline BA-137M & $7.8 \mathrm{c}+04$ & $9.7 \mathrm{c}+0.3$ & $9.0 \mathrm{e}-06$ & 0 & 0 & 0 \\
\hline CE-142 & 0.000027 & 0.000027 & 0.000027 & 0.000027 & 0.000027 & 0.000027 \\
\hline PM-147 & $9.4 c+0.3$ & $4.4 c-07$ & 0 & 0 & 0 & 0 \\
\hline EU-154 & $4.1 c+0.3$ & 2.9 & $9.1 c-32$ & 0 & 0 & 0 \\
\hline SUMTOT & $3.0 c+05$ & $3.4 c+04$ & 19 & 19 & 14 & 3.2 \\
\hline TOTAL & $3.0 \mathrm{c}+05$ & $3.4 c+04$ & 19 & 19 & 14 & 3.2 \\
\hline
\end{tabular}


Table A.2. Air hazard (cubic meters) of one metric ton of pressurized water reactor spent cucl versus time

Time (years)

Isotope

$1.0 \mathrm{e}+1$

$1.0 \mathrm{e}+2$

$1.0 \mathrm{e}+3$

$1.0 \mathrm{e}+4$

$1.0 \mathrm{e}+5$

$1.0 \mathrm{e}+6$

Activation products

\begin{tabular}{|c|c|c|c|c|c|c|}
\hline $\mathrm{H}-3$ & $7.5 c+08$ & $4.8 e+06$ & $5.5 e-16$ & 0 & 0 & 0 \\
\hline C-14 & $1.5 e+07$ & $1.4 \mathrm{c}+07$ & $1.3 e+07$ & $4.4 e+06$ & 81 & 0 \\
\hline CL-36 & $1.4 e+07$ & $1.4 e+07$ & $1.4 \mathrm{e}+07$ & $1.4 c+07$ & $1.1 e+07$ & $1.4 c+06$ \\
\hline FE-55 & $1.2 e+10$ & 0.47 & 0 & 0 & 0 & 0 \\
\hline CO-60 & $1.0 c+13$ & $7.5 e+07$ & 0 & 0 & 0 & 0 \\
\hline NI-59 & $1.9 e+08$ & $1.9 e+08$ & $1.9 c+08$ & $1.8 \mathrm{e}+08$ & $8.2 c+07$ & $3.4 c+04$ \\
\hline NI-63 & $3.0 \mathrm{e}+11$ & $1.5 c+11$ & $1.7 e+08$ & $6.2 \mathrm{e}-22$ & 0 & 0 \\
\hline ZR-93 & $6.5 c+07$ & $6.5 e+07$ & $6.5 c+07$ & $6.5 e+07$ & $6.2 c+07$ & $4.1 \mathrm{c}+07$ \\
\hline NB-93M & $2.7 c+07$ & $6.1 \mathrm{c}+07$ & $6.2 c+07$ & $6.1 c+07$ & $5.9 \mathrm{c}+07$ & $3.9 c+07$ \\
\hline NB-94 & $1.3 e+10$ & $1.3 e+10$ & $1.3 c+10$ & $9.2 c+09$ & $4.3 \mathrm{c}+08$ & 0.000019 \\
\hline MO-93 & $2.4 \mathrm{c}+08$ & $2.4 \mathrm{e}+08$ & $2.0 c+08$ & $3.3 c+07$ & 0.6 & 0 \\
\hline SB-125 & $1.4 c+11$ & 23 & 0 & 0 & 0 & 0 \\
\hline SUMTOT & $1.1 c+13$ & $1.7 e+11$ & $1.3 c+10$ & $9.6 \mathrm{c}+09$ & $6.4 c+08$ & $8.3 e+07$ \\
\hline TOTAL & $1.1 c+13$ & $1.7 \mathrm{e}+11$ & $1.3 c+10$ & $9.6 c+09$ & $6.4 c+08$ & $8.3 c+07$ \\
\hline \multicolumn{7}{|l|}{ Actinides } \\
\hline PB-209 & 0.62 & 4.8 & $6.6 c+02$ & $8.6 c+04$ & $\begin{array}{l}1.9 \mathrm{c}+06 \\
2.7 \mathrm{c}+11\end{array}$ & \\
\hline PB-210 & $1.1 \mathrm{e}+04$ & $3.6 c+06$ & $7.7 c+08$ & $3.3 c+10$ & $\begin{array}{l}2.7 \mathrm{e}+11 \\
1.1 \mathrm{c}+08\end{array}$ & $\begin{array}{l}1.2 e+11 \\
4.6 e+07\end{array}$ \\
\hline PB-214 & 36 & $2.6 e+0.3$ & $3.1 \mathrm{e}+05$ & $1.3 c+07$ & $\begin{array}{l}1.1 c+08 \\
53 c+09\end{array}$ & \\
\hline BI-210 & $2.2 \mathrm{c}+02$ & $7.1 \mathrm{e}+04$ & $1.5 e+07$ & $6.7 e+08$ & & $\begin{array}{l}2.3 c+09 \\
2.4 c+08\end{array}$ \\
\hline BI-213 & 31 & $2.4 c+02$ & $3.3 e+04$ & $4.3 c+06$ & $9.7 e+07$ & $2.4 c+08$ \\
\hline BI-214 & 36 & $2.6 \mathrm{e}+03$ & $3.1 c+05$ & $1.3 c+07$ & $1.1 \mathrm{c}+08$ & $4.6 c+07$ \\
\hline PO-210 & $(.4 c+03$ & $2.0 c+06$ & $4.4 c+08$ & $1.9 \mathrm{c}+10$ & $1.5 e+11$ & $6.6 e+10$ \\
\hline PO-213 & $1.2 e-08$ & $9.4 e-08$ & 0.000013 & 0.0017 & 0.038 & 0.092 \\
\hline PO-214 & $1.8 \mathrm{c}-06$ & 0.00013 & 0.015 & 0.67 & 5.3 & 2.3 \\
\hline PO-218 & 3.6 & $2.6 e+02$ & $3.1 c+04$ & $1.3 c+06$ & $1.1 \mathrm{c}+07$ & $4.6 c+06$ \\
\hline AT-217 & 0.0014 & 0.011 & 1.5 & $1.9 c+02$ & $4.3 e+(0.3$ & $1.0 \mathrm{e}+04$ \\
\hline RN-219 & $2.5 c+08$ & $2.0 \mathrm{e}+09$ & $1.8 c+10$ & $1.7 c+11$ & $1.1 \mathrm{e}+12$ & $1.4 \mathrm{e}+12$ \\
\hline RN-222 & $1.2 e+02$ & $8.7 c+03$ & $1.0 e+06$ & $4.5 c+07$ & $3.5 c+08$ & $1.5 c+08$ \\
\hline FR-221 & 1.2 & 9.6 & $1.3 c+03$ & $1.7 \mathrm{e}+05$ & $3.9 c+06$ & $9.4 c+06$ \\
\hline RA-225 & $2.5 e+0.3$ & $1.9 \mathrm{e}+04$ & $2.6 c+06$ & $3.4 c+08$ & $7.7 c+09$ & $1.9 c+10$ \\
\hline RA-226 & $1.8 c+05$ & $1.3 c+07$ & $1.5 c+09$ & $6.7 e+10$ & $5.3 c+11$ & $2.3 e+11$ \\
\hline AC-225 & $1.2 \mathrm{e}+04$ & $9.6 \mathrm{e}+04$ & $1.3 c+07$ & $1.7 e+09$ & $3.9 \mathrm{c}+10$ & $9.4 c+10$ \\
\hline TH-229 & $6.2 e+06$ & $4.8 c+07$ & $6.6 c+09$ & $8.6 c+11$ & $1.9 e+13$ & $4.7 e+13$ \\
\hline TH-230 & $1.6 c+09$ & $1.6 e+10$ & $2.1 c+11$ & $2.1 c+12$ & $1.3 e+13$ & $5.8 c+12$ \\
\hline TH-234 & $3.2 e+08$ & $3.2 e+08$ & $3.2 c+08$ & $3.2 c+08$ & $3.2 e+08$ & $3.2 c+08$ \\
\hline PA-233 & $5.6 c+07$ & $7.3 e+07$ & $1.7 e+08$ & $2.0 c+08$ & $2.0 c+08$ & $1.5 e+08$ \\
\hline PA-234M & $7.9 e+04$ & $7.9 e+04$ & $7.9 e+04$ & $7.9 e+04$ & $7.9 \mathrm{e}+04$ & $7.9 c+04$ \\
\hline $\mathrm{U}-233$ & $6.6 c+06$ & $4.5 c+07$ & $8.4 c+08$ & $1.2 e+10$ & $1.1 c+11$ & $2.3 c+11$ \\
\hline$U-234$ & $2.9 \mathrm{e}+11$ & $4.0 \mathrm{e}+11$ & $5.1 c+11$ & $5.0 c+11$ & $4.0 \mathrm{c}+11$ & $1.0 e+11$ \\
\hline U-236 & $6.4 c+10$ & $6.5 c+10$ & $6.8 e+10$ & $8.6 c+10$ & $9.8 c+10$ & $9.5 c+10$ \\
\hline $\mathrm{U}-23 \mathrm{O}$ & $1.1 \_+11$ & $1.1 a+11$ & $1.1 e+11$ & $11 c+11$ & $1.1 c+11$ & $1.1 \mathrm{e}+11$ \\
\hline
\end{tabular}


Table A.2. Air hazard (cubic meters) of one metric ton of pressurized water reactor spent fuel versus time (continued)

Time (years)

\begin{tabular}{|c|c|c|c|c|c|c|}
\hline \multirow{2}{*}{ Isotope } & & & & & & \\
\hline & $1.0 \mathrm{e}+1$ & $1.0 \mathrm{e}+2$ & $1.0 e+3$ & $1.0 \mathrm{e}+4$ & $1.0 \mathrm{c}+5$ & $1.0 \mathrm{c}+6$ \\
\hline NP-237 & $3.4 e+12$ & $4.4 c+12$ & $1.0 e+13$ & $1.2 e+13$ & $1.2 \mathrm{e}+13$ & $8.9 e+12$ \\
\hline NP-239 & $9.1 e+08$ & $9.1 \mathrm{e}+08$ & $8.3 c+08$ & $3.6 c+08$ & $7.6 c+04$ & 4.2 \\
\hline PU-238 & $3.5 e+16$ & $1.7 e+16$ & $1.8 \mathrm{e}+13$ & $6.7 e-06$ & 0 & 0 \\
\hline PU-239 & $5.4 e+15$ & $5.4 e+15$ & $5.3 e+15$ & $4.1 \mathrm{e}+15$ & $3.1 e+14$ & $1.4 \mathrm{e}+06$ \\
\hline PU-240 & $8.1 e+15$ & $8.0 \mathrm{e}+15$ & $7.3 e+15$ & $2.8 e+15$ & $2.0 \mathrm{e}+11$ & $7.6 c+06$ \\
\hline PU-241 & $2.6 e+16$ & $3.5 e+14$ & $4.9 e+10$ & $2.4 e+10$ & $1.5 e+07$ & $2.0 \mathrm{e}-25$ \\
\hline PU-242 & $2.9 e+13$ & $2.9 e+13$ & $2.9 e+13$ & $2.9 e+13$ & $2.5 c+13$ & $4.9 e+12$ \\
\hline AM-241 & $8.7 e+15$ & $1.9 e+16$ & $4.6 e+15$ & $3.6 c+11$ & $2.3 c+08$ & $3.2 \mathrm{c}-24$ \\
\hline $\mathrm{AM}-243$ & $9.1 e+13$ & $9.1 e+13$ & $8.3 e+13$ & $3.6 c+13$ & $7.6 c+09$ & $4.2 e+05$ \\
\hline CM-244 & $4.9 \mathrm{e}+15$ & $1.6 c+14$ & 0.17 & 0 & 0 & 0 \\
\hline SUMTOT & $8.8 c+16$ & $5.0 c+16$ & $1.7 e+16$ & $7.0 c+15$ & $3.9 \mathrm{e}+14$ & $7.0 e+13$ \\
\hline TOTAL & $8.8 e+16$ & $5.0 \mathrm{e}+16$ & $1.7 e+16$ & $7.0 c+15$ & $3.9 e+14$ & $7.0 \mathrm{e}+13$ \\
\hline \multicolumn{7}{|c|}{ Fission products } \\
\hline SE-79 & $4.1 e+09$ & $4.1 e+09$ & $4.0 c+09$ & $3.7 e+09$ & $1.4 c+09$ & $9.5 c+04$ \\
\hline $\mathrm{KR}-85$ & $1.6 e+10$ & $4.8 c+07$ & $2.6 \mathrm{e}-18$ & 0 & 0 & 0 \\
\hline SR-90 & $1.9 e+15$ & $2.2 \mathrm{e}+14$ & $1.1 \mathrm{e}+05$ & 0 & 0 & 0 \\
\hline$Y-90$ & $1.9 e+13$ & $2.2 c+12$ & $1.1 e+03$ & 0 & 0 & 0 \\
\hline ZR-93 & $4.5 e+08$ & $4.5 c+08$ & $4.5 c+08$ & $4.5 c+08$ & $4.3 c+08$ & $2.9 c+08$ \\
\hline NB-93M & $1.9 e+08$ & $4.3 c+08$ & $4.3 c+08$ & $4.3 c+08$ & $4.1 \mathrm{e}+08$ & $2.7 c+08$ \\
\hline TC-99 & $6.6 e+09$ & $6.6 e+09$ & $6.6 c+09$ & $6.4 c+09$ & $4.8 c+09$ & $2.5 e+08$ \\
\hline PD-107 & $1.1 \mathrm{e}+09$ & $1.1 \mathrm{c}+09$ & $1.1 c+09$ & $1.1 c+09$ & $1.1 \mathrm{e}+09$ & $1.0 c+09$ \\
\hline SN-126 & $7.6 c+09$ & $7.6 c+09$ & $7.5 e+09$ & $7.1 c+09$ & $3.8 c+09$ & $7.4 e+06$ \\
\hline SB-126 & $1.1 \mathrm{e}+09$ & $1.1 \mathrm{c}+09$ & $1.1 c+09$ & $9.9 e+08$ & $5.3 e+08$ & $1.0 e+06$ \\
\hline SB-126M & $2.5 e+07$ & $2.5 e+07$ & $2.5 e+07$ & $2.4 c+07$ & $1.3 e+07$ & $2.5 c+04$ \\
\hline I-129 & $1.6 e+09$ & $1.6 c+09$ & $1.6 e+09$ & $1.6 e+09$ & $1.6 e+09$ & $1.5 e+09$ \\
\hline CS-134 & $1.4 e+13$ & 0.99 & 0 & 0 & 0 & 0 \\
\hline CS-135 & $1.2 c+08$ & $1.2 \mathrm{e}+08$ & $1.2 \mathrm{e}+08$ & $1.2 \mathrm{e}+08$ & $1.2 e+08$ & $8.9 e+07$ \\
\hline CS-137 & $1.6 e+14$ & $2.1 \mathrm{e}+13$ & $1.9 e+04$ & 0 & 0 & 0 \\
\hline BA- $137 \mathrm{M}$ & $2.6 c+12$ & $3.2 c+11$ & $3.0 \mathrm{c}+02$ & 0 & 0 & 0 \\
\hline CE-142 & $1.4 \mathrm{e}+09$ & $1.4 c+09$ & $1.4 \mathrm{e}+09$ & $1.4 c+09$ & $1.4 c+09$ & $1.4 c+09$ \\
\hline PM-147 & $4.7 e+12$ & $2.2 e+02$ & 0 & 0 & 0 & 0 \\
\hline EU-154 & $4.1 e+13$ & $2.9 \mathrm{c}+10$ & $9.1 \mathrm{e}-22$ & 0 & 0 & 0 \\
\hline SUMTOT & $2.2 \mathrm{c}+15$ & $2.5 c+14$ & $2.4 c+10$ & $2.3 c+10$ & $1.5 c+10$ & $4.8 c+09$ \\
\hline TOTAL & $2.2 \mathrm{e}+15$ & $2.5 c+14$ & $2.4 c+10$ & $2.3 e+10$ & $1.5 c+10$ & $4.8 c+09$ \\
\hline
\end{tabular}


Table A.3. Water hazard (cubic meters) of one metric ton of pressurized water reactor spent fuel versus time

Time (years)

\begin{tabular}{|c|c|c|c|c|c|c|}
\hline Isotope & $1.0 \mathrm{e}+1$ & $1.0 \mathrm{e}+2$ & $1.0 \mathrm{e}+3$ & $1.0 c+4$ & $1.0 \mathrm{c}+5$ & $1.0 \mathrm{e}+6$ \\
\hline \multicolumn{7}{|c|}{ Activation products } \\
\hline $\mathrm{H}-3$ & $5.0 e+04$ & $3.2 \mathrm{e}+02$ & $3.7 \mathrm{e}-20$ & 0 & () & 0 \\
\hline C-14 & $18 . e+03$ & $1.8 \mathrm{c}+03$ & $1.6 e+03$ & $5.4 c+02$ & 0.01 & 0 \\
\hline CL-36 & $1.9 \mathrm{e}+02$ & $1.9 e+02$ & $1.9 \mathrm{c}+02$ & $1.9 c+02$ & $1.5 c+02$ & 19 \\
\hline FE-55 & $4.6 e+05$ & 0.000017 & 0 & 0 & 0 & 0 \\
\hline $\mathrm{CO}-60$ & $1.0 \mathrm{e}+08$ & $7.5 \mathrm{e}+02$ & 0 & 0 & 0 & 0 \\
\hline NI-59 & $1.9 e+04$ & $1.9 e+04$ & $1.9 \mathrm{e}+04$ & $1.8 \mathrm{c}+04$ & $8.2 \mathrm{c}+03$ & 3.4 \\
\hline NI-63 & $2.0 c+07$ & $1.0 \mathrm{e}+07$ & $1.2 \mathrm{c}+04$ & $4.1 e-26$ & 0 & 0 \\
\hline ZR-93 & $3.2 \mathrm{e}+02$ & $3.2 \mathrm{c}+02$ & $3.2 \mathrm{c}+02$ & $3.2 c+02$ & $3.1 \mathrm{e}+02$ & $2.1 \mathrm{e}+02$ \\
\hline NB-93M & $2.7 \mathrm{e}+02$ & $6.1 c+02$ & $6.2 c+02$ & $6.1 c+02$ & $5.9 \mathrm{c}+02$ & $3.9 c+02$ \\
\hline NB-94 & $4.3 c+05$ & $4.3 c+05$ & $4.2 c+05$ & $3.1 e+05$ & $1.4 c+04$ & $6.4 c-10$ \\
\hline M0-93 & $8.0 c+03$ & $7.9 \mathrm{e}+03$ & $6.6 c+03$ & $1.1 \mathrm{c}+03$ & 0.00002 & 0 \\
\hline SB-125 & $1.2 \mathrm{c}+06$ & 0.0002 & 0 & 0 & 0 & 0 \\
\hline SUMTOT & $1.3 \mathrm{c}+08$ & $1.1 \mathrm{e}+07$ & $4.6 \mathrm{c}+05$ & $3.3 c+05$ & $2.3 c+04$ & $6.2 c+02$ \\
\hline TOTAL & $1.3 e+08$ & $1.1 \mathrm{c}+07$ & $4.6 e+05$ & $3.3 e+05$ & $2.3 e+04$ & $6.2 c+02$ \\
\hline
\end{tabular}

Actinides

$\begin{array}{lllllll}\text { PB-209 } & 0.000041 & 0.00032 & 0.044 & 5.7 & 1.3 \mathrm{c}+02 & 3.1 \mathrm{c}+02 \\ \text { PB-210 } & 0.45 & 1.4 \mathrm{c}+02 & 3.1 \mathrm{c}+04 & 1.3 \mathrm{e}+06 & 1.1 \mathrm{c}+07 & 4.6 \mathrm{c}+06 \\ \text { PB-214 } & 0.00072 & 0.052 & 6.2 & 2.7 \mathrm{c}+02 & 2.1 \mathrm{c}+03 & 9.3 \mathrm{c}+02 \\ \text { BI-210 } & 0.0011 & 0.36 & 77 & 3.3 \mathrm{c}+03 & 2.7 \mathrm{c}+04 & 1.2 \mathrm{c}+04 \\ \text { BI-213 } & 0.00025 & 0.0019 & 0.26 & 34 & 7.7 \mathrm{c}+02 & 1.9 \mathrm{c}+03 \\ \text { BI-214 } & 0.0006 & 0.043 & 5.2 & 2.2 \mathrm{c}+02 & 1.8 \mathrm{c}+03 & 7.7 \mathrm{c}+02 \\ \text { PO-210 } & 0.064 & 20 & 4.4 \mathrm{c}+03 & 1.9 \mathrm{c}+05 & 1.5 \mathrm{c}+06 & 6.6 \mathrm{c}+05 \\ \text { PO-213 } & 4.0 \mathrm{c}-13 & 3.1 \mathrm{c}-12 & 4.3 \mathrm{c}-10 & 5.6 \mathrm{c}-08 & 1.3 \mathrm{e}-06 & 3.1 \mathrm{c}-06 \\ \text { PO-214 } & 5.1 \mathrm{c}-11 & 3.7 \mathrm{e}-09 & 4.4 \mathrm{c}-07 & 0.000019 & 0.00015 & 0.000066 \\ \text { PO-218 } & 0.00009 & 0.0065 & 0.77 & 33 & 2.7 \mathrm{c}+02 & 1.2 \mathrm{c}+02 \\ \text { AT-217 } & 2.1 \mathrm{e}-07 & 1.6 \mathrm{c}-06 & 0.00022 & 0.029 & 0.65 & 1.6 \\ \text { RN-219 } & 1.7 \mathrm{e}+02 & 1.3 \mathrm{c}+03 & 1.2 \mathrm{c}+04 & 1.1 \mathrm{c}+05 & 7.5 \mathrm{c}+05 & 9.3 \mathrm{c}+05 \\ \text { RN-222 } & 3.6 \mathrm{e}-07 & 0.000026 & 0.0031 & 0.13 & 1.1 & 0.46 \\ \text { FR-221 } & 0.00015 & 0.0012 & 0.16 & 21 & 4.8 \mathrm{c}+02 & 1.2 \mathrm{c}+03 \\ \text { RA-225 } & 0.25 & 1.9 & 2.6 \mathrm{c}+02 & 3.4 \mathrm{c}+04 & 7.7 \mathrm{c}+05 & 1.9 \mathrm{c}+06 \\ \text { RA-226 } & 12 & 8.7 \mathrm{c}+02 & 1.0 \mathrm{c}+05 & 4.5 \mathrm{c}+06 & 3.5 \mathrm{c}+07 & 1.5 \mathrm{c}+07 \\ \text { AC-225 } & 0.025 & 0.19 & 26 & 3.4 \mathrm{c}+03 & 7.7 \mathrm{c}+04 & 1.9 \mathrm{c}+05 \\ \text { TH-229 } & 0.31 & 2.4 & 3.3 \mathrm{c}+02 & 4.3 \mathrm{c}+04 & 9.7 \mathrm{c}+05 & 2.4 \mathrm{c}+06 \\ \text { TH-230 } & 64 & 6.3 \mathrm{c}+02 & 8.6 \mathrm{c}+03 & 8.6 \mathrm{c}+04 & 5.3 \mathrm{c}+05 & 2.3 \mathrm{c}+05 \\ \text { TH-234 } & 1.6 \mathrm{c}+04 & 1.6 \mathrm{c}+04 & 1.6 \mathrm{c}+04 & 1.6 \mathrm{c}+04 & 1.6 \mathrm{c}+04 & 1.6 \mathrm{c}+04 \\ \text { PA-233 } & 3.4 \mathrm{e}+03 & 4.4 \mathrm{c}+03 & 1.0 \mathrm{c}+04 & 1.2 \mathrm{c}+04 & 1.2 \mathrm{c}+04 & 8.9 \mathrm{c}+03 \\ \text { PA-234M } & 16 & 16 & 16 & 16 & 16 & 16 \\ \text { U-233 } & 0.88 & 5.9 & 1.1 \mathrm{c}+02 & 1.7 \mathrm{c}+03 & 1.4 \mathrm{c}+04 & 3.1 \mathrm{c}+04 \\ \text { U-234 } & 3.8 \mathrm{e}+04 & 5.3 \mathrm{c}+04 & 6.7 \mathrm{c}+04 & 6.6 \mathrm{c}+04 & 5.4 \mathrm{c}+04 & 1.4 \mathrm{c}+04\end{array}$


Table A.3. Water hazard (cubic meters) of one metric ton of pressurized water reactor spent fuel versus time (continued)

Time (years)

\begin{tabular}{lllllll}
\multicolumn{1}{c}{ Isotope } & $1.0 \mathrm{e}+1$ & $1.0 \mathrm{e}+2$ & $1.0 \mathrm{e}+3$ & $1.0 \mathrm{e}+4$ & $1.0 \mathrm{e}+5$ & $1.0 \mathrm{e}+6$ \\
\hline U-236 & $8.6 \mathrm{e}+03$ & $8.6 \mathrm{e}+03$ & $9.0 \mathrm{e}+03$ & $1.2 \mathrm{e}+04$ & $1.3 \mathrm{e}+04$ & $1.3 \mathrm{e}+04$ \\
U-238 & $7.9 \mathrm{e}+03$ & $7.9 \mathrm{e}+03$ & $7.9 \mathrm{e}+03$ & $7.9 \mathrm{e}+03$ & $7.9 \mathrm{e}+03$ & $7.9 \mathrm{e}+03$ \\
NP-237 & $1.1 \mathrm{e}+05$ & $1.5 \mathrm{e}+05$ & $3.5 \mathrm{e}+05$ & $4.1 \mathrm{e}+05$ & $3.9 \mathrm{e}+05$ & $3.0 \mathrm{e}+05$ \\
NP-239 & $1.8 \mathrm{e}+05$ & $1.8 \mathrm{e}+05$ & $1.7 \mathrm{e}+05$ & $7.1 \mathrm{e}+04$ & 15 & 0.00084 \\
PU-238 & $4.8 \mathrm{e}+08$ & $2.4 \mathrm{e}+08$ & $2.5 \mathrm{e}+05$ & $9.3 \mathrm{e}-14$ & 0 & 0 \\
PU-239 & $6.5 \mathrm{e}+07$ & $6.5 \mathrm{e}+07$ & $6.4 \mathrm{e}+07$ & $5.0 \mathrm{e}+07$ & $3.8 \mathrm{c}+06$ & 0.017 \\
PU-240 & $9.7 \mathrm{e}+07$ & $9.7 \mathrm{e}+07$ & $8.8 \mathrm{e}+07$ & $3.4 \mathrm{e}+07$ & $2.4 \mathrm{e}+03$ & 0.091 \\
PU-241 & $4.0 \mathrm{e}+08$ & $5.2 \mathrm{e}+06$ & $7.4 \mathrm{e}+02$ & $3.5 \mathrm{e}+02$ & 0.23 & $3.0 \mathrm{e}-33$ \\
PU-242 & $3.5 \mathrm{e}+05$ & $3.5 \mathrm{e}+05$ & $3.5 \mathrm{e}+05$ & $3.5 \mathrm{e}+05$ & $3.0 \mathrm{e}+05$ & $5.9 \mathrm{e}+04$ \\
AM-241 & $4.4 \mathrm{e}+08$ & $9.6 \mathrm{e}+08$ & $2.3 \mathrm{e}+08$ & $1.8 \mathrm{e}+04$ & 11 & $1.6 \mathrm{e}-31$ \\
AM-243 & $4.6 \mathrm{e}+06$ & $4.5 \mathrm{e}+06$ & $4.2 \mathrm{e}+06$ & $1.8 \mathrm{c}+06$ & $3.8 \mathrm{e}+02$ & 0.021 \\
CM-244 & $2.1 \mathrm{e}+08$ & $6.7 \mathrm{e}+06$ & $7.4 \mathrm{e}-09$ & 0 & 0 & 0 \\
SUMTOT & $1.7 \mathrm{e}+09$ & $1.4 \mathrm{e}+09$ & $3.9 \mathrm{e}+08$ & $9.2 \mathrm{e}+07$ & $5.5 \mathrm{c}+07$ & $2.7 \mathrm{c}+07$ \\
TOTAL & $1.7 \mathrm{e}+09$ & $1.4 \mathrm{c}+09$ & $3.9 \mathrm{c}+08$ & $9.2 \mathrm{e}+07$ & $5.5 \mathrm{c}+07$ & $2.7 \mathrm{e}+07$
\end{tabular}

Fission products

\begin{tabular}{|c|c|c|c|c|c|c|}
\hline SE-79 & $1.4 \mathrm{e}+05$ & $1.4 c+05$ & $1.3 c+05$ & $1.2 e+05$ & $4.7 \mathrm{e}+04$ & 3.2 \\
\hline $\mathrm{KR}-85$ & $4.9 c+03$ & 14 & $7.7 \mathrm{e}-25$ & 0 & 0 & 0 \\
\hline SR-90 & $1.9 e+11$ & $2.2 c+10$ & 11 & 0 & 0 & 0 \\
\hline Y-90 & $2.9 e+09$ & $3.4 c+08$ & 0.17 & 0 & 0 & 0 \\
\hline ZR-93 & $2.3 e+03$ & $2.3 c+0.3$ & $2.3 c+03$ & $2.3 c+03$ & $2.2 c+03$ & $1.4 c+0.3$ \\
\hline NB-93M & $1.9 e+03$ & $4.3 e+0.3$ & $4.3 e+0.3$ & $4.3 e+03$ & $4.1 \mathrm{e}+03$ & $2.7 e+03$ \\
\hline TC-99 & $6.6 e+04$ & $6.6 c+04$ & $6.6 e+04$ & $6.4 c+04$ & $4.8 c+04$ & $2.5 c+0.3$ \\
\hline PD-107 & $3.7 e+04$ & $3.7 c+04$ & $3.7 e+04$ & $3.7 e+04$ & $3.7 c+04$ & $3.3 c+04$ \\
\hline $\mathrm{SN}-126$ & $2.5 e+05$ & $2.5 e+05$ & $2.5 e+05$ & $2.4 e+05$ & $1.3 \mathrm{e}+05$ & $2.5 e+02$ \\
\hline SB-126 & $3.5 e+04$ & $3.5 c+04$ & $3.5 c+04$ & $3.3 e+04$ & $1.8 \mathrm{e}+04$ & 35 \\
\hline SB-126M & 0.76 & 0.76 & 0.75 & 0.71 & 0.38 & 0.00074 \\
\hline I-129 & $5.2 \mathrm{e}+05$ & $5.2 \mathrm{c}+05$ & $5.2 e+05$ & $5.2 e+05$ & $5.2 \mathrm{e}+05$ & $5.0 \mathrm{c}+05$ \\
\hline CS-134 & $6.1 e+08$ & 0.000044 & 0 & 0 & () & 0 \\
\hline CS-135 & $3.6 e+03$ & $3.6 e+03$ & $3.6 c+03$ & $3.6 e+03$ & $3.5 c+03$ & $2.7 c+0.3$ \\
\hline CS-137 & $4.1 e+09$ & $5.1 e+08$ & 0.48 & 0 & 0 & 0 \\
\hline BA-137M & $7.8 c+04$ & $9.7 e+03$ & $9.0 \mathrm{c}-06$ & 0 & 0 & 0 \\
\hline CE-142 & $9.0 \mathrm{c}+02$ & $9.0 \mathrm{e}+02$ & $9.0 \mathrm{c}+02$ & $9.0 \mathrm{e}+02$ & $9.0 \mathrm{e}+02$ & $9.0 c+02$ \\
\hline PM-147 & $4.7 c+07$ & 0.0022 & 0 & 0 & 0 & 0 \\
\hline EU-154 & $2.0 e+08$ & $1.4 c+05$ & $4.5 e-27$ & 0 & 0 & 0 \\
\hline SUMTOT & $2.0 \mathrm{e}+11$ & $2.3 e+10$ & $1.1 e+06$ & $1.0 \mathrm{e}+06$ & $8.1 e+05$ & $5.4 e+05$ \\
\hline TOTAL & $2.0 \mathrm{e}+11$ & $2.3 e+10$ & $1.1 e+06$ & $1.0 \mathrm{e}+06$ & $8.1 c+05$ & $5.4 \mathrm{e}+05$ \\
\hline
\end{tabular}


Table A.4. EPA hazard (multiples of EPA release limits) of one metric ton of pressurized water reactor spent fuel versus time

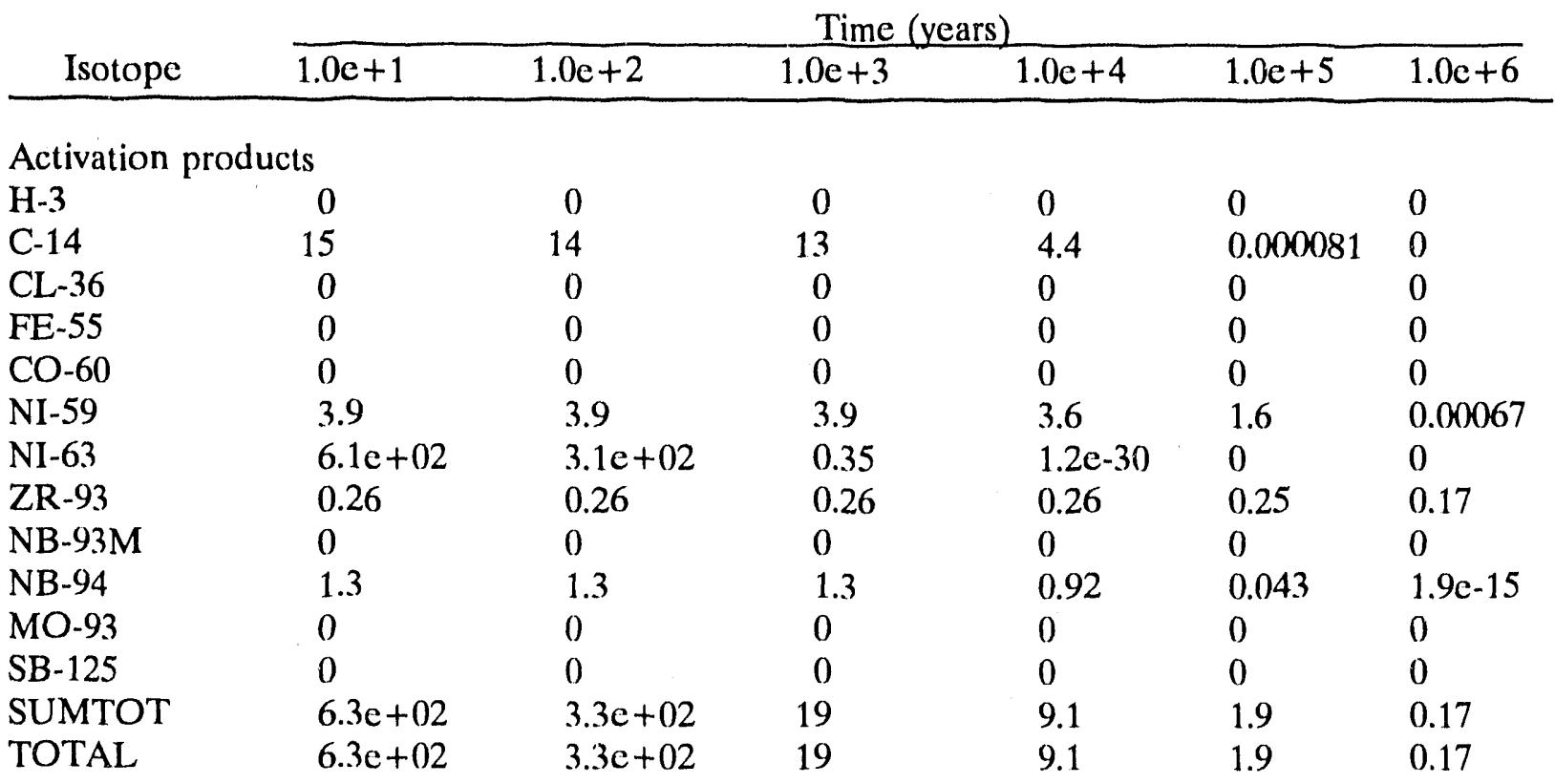

Actinides

$\begin{array}{lllllll}\text { PB-209 } & 0 & 0 & 0 & 0 & 0 & 0 \\ \text { PB-210 } & 4.5 \mathrm{e}-08 & 0.000014 & 0.0031 & 0.13 & 1.1 & 0.46 \\ \text { PB-214 } & 0 & 0 & 0 & 0 & 0 & 0 \\ \text { BI-210 } & 0 & 0 & 0 & 0 & 0 & 0 \\ \text { BI-213 } & 0 & 0 & 0 & 0 & 0 & 0 \\ \text { BI-214 } & 0 & 0 & 0 & 0 & 0 & 0 \\ \text { PO-210 } & 0 & 0 & 0 & 0 & 0 & 0 \\ \text { PO-213 } & 0 & 0 & 0 & 0 & 0 & 0 \\ \text { PO-214 } & 0 & 0 & 0 & 0 & 0 & 0 \\ \text { PO-218 } & 0 & 0 & 0 & 0 & 0 & 0 \\ \text { AT-217 } & 0 & 0 & 0 & 0 & 0 & 0 \\ \text { RN-219 } & 0 & 0 & 0 & 0 & 0 & 0 \\ \text { RN-222 } & 0 & 0 & 0 & 0 & 0 & 0 \\ \text { FR-221 } & 0 & 0 & 0 & 0 & 0 & 0 \\ \text { RA-225 } & 0 & 0 & 0 & 0 & 0 & 0 \\ \text { RA-226 } & 3.6 \mathrm{c}-06 & 0.00026 & 0.031 & 1.3 & 11 & 4.6 \\ \text { AC-225 } & 0 & 0 & 0 & 0 & 0 & 0 \\ \text { TH-229 } & 1.2 \mathrm{e}-06 & 9.6 \mathrm{c}-06 & 0.0013 & 0.17 & 3.9 & 9.4 \\ \text { TH-230 } & 0.013 & 0.13 & 1.7 & 17 & 1.1 \mathrm{e}+02 & 46 \\ \text { TH-234 } & 0 & 0 & 0 & 0 & 0 & 0 \\ \text { PA-233 } & 0 & 0 & 0 & 0 & 0 & 0 \\ \text { PA-234M } & 0 & 0 & 0 & 0 & 0 & 0 \\ \text { U-233 } & 0.00027 & 0.0018 & 0.034 & 0.5 & 4.2 & 9.4 \\ \text { U-234 } & 12 & 16 & 20 & 20 & 16 & 4.2 \\ \text { U-236 } & 2.6 & 2.6 & 2.7 & 3.5 & 3.9 & 3.8\end{array}$


Table A.4. EPA hazard (multiples of EPA release limits) of one metric ton of pressurized water reactor spent fuel versus time (continued)

\begin{tabular}{|c|c|c|c|c|c|c|}
\hline \multirow{2}{*}{ Isotope } & \multicolumn{6}{|c|}{ Time (years) } \\
\hline & $1.0 e+1$ & $1.0 \mathrm{e}+2$ & $1.0 \mathrm{e}+3$ & $1.0 \mathrm{e}+4$ & $1.0 \mathrm{e}+5$ & $1.0 \mathrm{e}+6$ \\
\hline $\mathrm{U}-238$ & 3.2 & 3.2 & 3.2 & 3.2 & 3.2 & 3.2 \\
\hline NP-237 & 3.4 & 4.4 & 10 & 12 & 12 & 8.9 \\
\hline NP-239 & 0 & 0 & 0 & 0 & 0 & 0 \\
\hline PU-238 & $2.4 \mathrm{e}+04$ & $1.2 \mathrm{e}+04$ & 13 & $4.7 \mathrm{e}-18$ & 0 & 0 \\
\hline PU-239 & $3.3 e+03$ & $3.3 e+03$ & $3.2 e+03$ & $2.5 e+03$ & $1.9 e+02$ & $8.4 \mathrm{e}-07$ \\
\hline PU-240 & $4.8 e+03$ & $4.8 e+03$ & $4.4 e+03$ & $1.7 e+03$ & 0.12 & $4.6 \mathrm{e}-06$ \\
\hline PU-241 & 0 & 0 & 0 & 0 & 0 & 0 \\
\hline PU-242 & 18 & 18 & 18 & 17 & 15 & 2.9 \\
\hline AM-241 & $1.7 e+04$ & $3.8 c+04$ & $9.1 \mathrm{e}+03$ & 0.71 & 0.00046 & $6.4 \mathrm{e}-36$ \\
\hline AM-243 & $1.8 c+02$ & $1.8 \mathrm{e}+02$ & $1.7 \mathrm{e}+02$ & 71 & 0.015 & $8.4 \mathrm{c}-07$ \\
\hline CM-244 & 0 & 0 & 0 & 0 & 0 & 0 \\
\hline SUMTOT & $5.0 \mathrm{e}+04$ & $5.9 e+04$ & $1.7 e+04$ & $4.3 c+0.3$ & $3.6 c+02$ & 93 \\
\hline TOTAL & $5.0 \mathrm{e}+04$ & $5.9 e+04$ & $1.7 \mathrm{c}+04$ & $4.3 c+03$ & $3.6 c+02$ & 93 \\
\hline \multicolumn{7}{|c|}{ Fission products } \\
\hline SE-79 & 0 & 0 & 0 & 0 & 0 & () \\
\hline KR-85 & 0 & 0 & 0 & 0 & () & 0 \\
\hline SR-90 & $5.7 e+04$ & $6.7 e+03$ & $3.4 c-06$ & 0 & 0 & 0 \\
\hline Y.90 & 0 & 0 & 0 & 0 & 0 & 0 \\
\hline ZR-93 & 1.8 & 1.8 & 1.8 & 1.8 & 1.7 & 1.2 \\
\hline NB-93M & 0 & 0 & 0 & 0 & 0 & 0 \\
\hline TC-99 & 1.3 & 1.3 & 1.3 & 1.3 & 0.95 & 0.051 \\
\hline PD-107 & 0 & 0 & 0 & 0 & 0 & 0 \\
\hline SN-126 & 0.76 & 0.76 & 0.75 & 0.71 & 0.38 & 0.00074 \\
\hline SB-126 & 0 & 0 & 0 & 0 & 0 & 0 \\
\hline SB-126M & 0 & 0 & 0 & 0 & 0 & 0 \\
\hline I-129 & 0.31 & 0.31 & 0.31 & 0.31 & 0.31 & 0.3 \\
\hline CS-134 & 0 & 0 & 0 & 0 & 0 & 0 \\
\hline CS-135 & 0.36 & 0.36 & 0.36 & 0.36 & 0.35 & 0.27 \\
\hline CS-137 & $8.2 e+04$ & $1 e+04$ & $9.6 c-06$ & 0 & 0 & 0 \\
\hline BA-137M & 0 & 0 & 0 & 0 & 0 & 0 \\
\hline CE-142 & 0 & 0 & 0 & 0 & 0 & 0 \\
\hline PM-147 & 0 & 0 & 0 & 0 & 0 & 0 \\
\hline EU-154 & 0 & 0 & 0 & 0 & 0 & 0 \\
\hline SUMTOT & $1.4 \mathrm{e}+05$ & $1.7 e+04$ & 4.6 & 4.5 & 3.7 & 1.8 \\
\hline TOTAL & $1.4 e+05$ & $1.7 c+04$ & 4.6 & 4.5 & 3.7 & 1.8 \\
\hline
\end{tabular}


ORNL/M-1822

UC 510, 810

\section{INTERNAL DISTRIBUTION}

1. J. M. Begovich

2. W. D. Bond

3. A. G. Croff

4-13. C. W. Forsberg

14. V. M. Green

15. R. K. Genung

16. J. M. Googin

17. H. R. Hightower

18. V. T. Hinkel

19-23. G. E. Michaels

24. F. J. Homan

25. J. C. Mailen

26. J. P. Nichols
27. K. J. Notz

28. M. G. Stewart

29. T. D. Welch

30. J. D. White

31. R. G. Wymer

32-33. Central Research Library

34-35. Laboratory Records

36. Laboratory Records, RC

37. ORNL Y-12 Technical Library, Document Reference Section

38. ORNL Patent Section

\section{EXTERNAL DISTRIBUTION}

39. C. A. Anderson, Associate Staff Director, National Research Council, 2101 Constitution Avenue NW, Harris Building/Room 456, Washington, DC 20418

40. E. Arthur, Los Alamos National Laboratory, P.O. Box 1663, Los Alamos, NM 87545

41. J. Bates, Argonne National Laboratory, 9700 S. Cass Avenue, Argonne, IL 60439

42. J. E. Battles, Argonne National Laboratory, 9700 S. Cass Avenue, Argonne, IL 60439

43. F. Bingham, Yucca Mountain Project Office, 101 Convention Center Drive, Suite 407, Las Vegas, NV 89109

44. L. Blankner, U.S. Department of Energy, Oak Ridge Field Office, Oak Ridge, TN 37831

45. J. Book, Yucca Mountain Project Office, 101 Convention Center Drive, Suite 407, Las Vegas, NV 89109 
46. K. Boomer, Westinghouse Hanford Company, P.O. Box 1970, Richland, WA 99352

47. T. J. Burke, Johns Hopkins University, Gisman Hall, Room 312, History Department, 34th and Charles St., Baltimore, Maryland 21218

48. H. C. Burkholder, Pacific Northwest Laboratory, P.O. Box 999, Richland, WA 99342

49. J. Burns, J. K. Research Associates, 430)3 North 11th Street, Arlington, VA 22201

50. L. Carter, 4522 Lowell St., NW, Washington, D.C. 20016

51. Y. Chang, Argonne National Laboratory, 9700) S. Cass Avenue, Argonne, IL 60439

52. N. Chipman, WINCO-INEL, P.O. Box 4000), Mail Stop 5213, Idaho Falls, ID 83403

53. Jor-Shan Choi, Lawrence Livermore National Laboratory, P.O. Box 808, Livermore, CA 94550

54. G. Choppin, Chemistry Department, Separations Science Enginecring, Florida State University, Tallahassec, FL 32306

55. W. Colglazier, University of Tennessee, Director, Waste Management Research and Education Institute, RM 327, South Stadium Hall, University of Tennessec, Knoxville, TN 37996-(0710

56. T. Cotton, J. K. Rescarch Associates, 4303 North 11th Strect, Arlington, VA 22201

57. L. Duffy, U. S. Department of Energy, ERWM, 1000) Independenee Avenue, SW, Washington, D.C. 20585

58. L. G. Eriksson, Senior Staff Officer, National Research Council, Harris Building, Room 466, 2101 Constitution Avenue NW, Washington, D.C. 20418

59. H. K. Forsen, Bechtel Group, 50 Beale Street, P.O. Box 193965, San Franciseo, CA $94119-3965$

60. C. Frank, DOE/EM, U.S. Department of Energy, 1000 Independence Avenue, S.W., Washington, DC 20585

61. B. J. Garrick, Pickard, Lowe, \& Garrick, Inc., Suite 400, 4590 MacAuthur Blvd., Newport Beach, CA 92660 
62. J. H. Gladden, Senior Secretary, National Research Council, Harris Building, Room 466, 2101 Constitution Avenue NW, Washington, D.C. 20418

63. M. W. Golay, Dept. of Nuclear Engineering, Massachusetts Institute of Technology, 77 Massachusetts Avenue, Cambridge, MA 02139

64-73. F. Goldner, U.S. Department of Energy, NE-45, 19901 Germantown Road, Germantown, MD 20874

74. J. Griffith, U.S. Department of Energy, 19901 Germantown Road, Germantown, MD 20874

75. H. A. Grunder, Continuous Electron Beam Accelerator Facility, 1200 Jefferson Ave., Newport News, VA 23606

76. G. L. Gyorey, General Electric Company, 6835 Via Del Oro, San Jose, CA 95153-5354

77. W. Halsey, Lawrence Livermore National Laboratory, P.O. Box 808, Livermore, CA 94550

78. L. Charles Hebel, Xerox Corporation, 3333 Coyote Hill Road, Palo Alto, CA 94304

79. P. Horwitz, Argonne National Laboratory, 9700 S. Cass Avenue, Argonne, IL 60439

80. Thomas O. Hunter, Sandia National Laboratories, P.O. Box 5800, Albuquerque, NM 87185

81. T. Isaacs, U.S. Department of Energy, DOE/RW, 1000 Independence Avenue, Washington, DC 20585

82. L. Jardine, Lawrence Livermore National Laboratory, P.O. Box 808, Livermore, CA 94550

83. P. Johnson, Office of Technical Assessments, United States Congress, Washington, D.C. 20510

84. T. Johnson, Argonne National Laboratory, 9700 S. Cass Avenue, Argonne, IL 60439

85. C. H. Kang, Massachusetts Institute of Technology, Plasma Fusion Center, NW16-139, 190 Albany St., Cambridge, MA 02139 
86. M. S. Kazimi, Massachusetts Institute of Technology, Department of Nuclear Engineering, Bld. 24-102, Cambridge, MA 02139

87. E. E. Kintner, Bradley Hill Road, P.O. Box 682, Norwich, VT 05055

88. D. Knecht, Idaho Chemical Processing Plant, WINCO, P.O. Box 4000, Idaho Falls, ID 83403

89. J. J. Laidler, Argonne National Laboratory, 9700 S. Cass Avenuc, Argonne, IL 60439

90. R. A. Langley, British Nuclear Fuels, plc. Inc., Suite 950, 9302 Lec Highway, Fairfax, VA 22031-1207

91. W. L. Lee, Lawrence Berkeley Laboratory, University of California, 1 Cyclotron Road, Berkcley, CA 94720

92. E. Mason, 46 Admirals Lane, P.O. Box 451, Osterville, MA 02655

93. A. McCabe, University of Tennessee, Energy, Environment and Resources Center, 327 South Stadium Hall, Knoxville, TN 37996

94. F. W. McLafferty, Cornell University, 260 Baker Lab., Ithaca, NY 14853

95. C. McPheeters, Argonne National Laboratory, 9700 S. Cass Avenue, Argonne, IL 60439

96. A. C. Millunzi, U. S. Department of Energy, NE-40, Washington, DC 20585

97. D. Orth, Westinghouse Savannah River Company, P.O. Box 616, Aiken, SC 29802

98. A. Pasternak, University of California, Lawrence Livermore National Laboratory, P.O. Box 808, Livermore, CA 94550

99. T. H. Pigford, University of California at Berkeley, Dept. of Nuclear Engineering, Berkeley, CA 94720

100. L. D. Ramspott, Lawrence Livermore National Laboratory, University of California, P.O. Box 808, L-209, Livermore, CA 94550

101. N. C. Rasmussen, Bld. 24, Department of Nuclear Engineering, Massachusetts Institute of Technology, 77 Massachusetts Avenue, Cambridge, MA 02139

102. J. Rawlins, Westinghouse Hanford Company, P.O. Box 1970, Richland, WA 99352 
103. Dan W. Reicher, Natural Resources Defense Council, 1350 New York Avenue, N.W., Washington, DC 20005

104. B. Rock, U.S. Department of Energy, 19901 Germantown Road, Germantown, MD 20874

105. E. Rodwell, Electric Power Research Institute, 3412 Hillview Avenue, Palo Alto, CA 94303

106. S. Rosen, U.S. Department of Energy, DOE/NE, 19901 Germantown Road, Germantown, MD 20874

107. W. Sprecher, U.S. Department of Energy, RW-42, 1000 Independence Avenue, SW, Washington, DC 20585

108. I. Taylor, General Electric Company, 6835 Via Del Oro, P.O. Box 530954, San Jose, CA 95153-5354

109. M. Thompson, General Electric Company, 6835 Via Del Oro, P.O. Box 53095, San Jose, CA 95153-5354

110. G. Van Tuyle, Brookhaven National Laboratory, Upton, Long Island, New York 11973

111. J. E. Watson, Department of Environmental Science and Engineering, University of North Carolina, Chapel Hill, NC 27599-7400

112. C. Whipple, Board on Radioactive Waste Management, National Research Council, 2101 Constitution Avenue, N.W., Washington, DC 20418

113. J. Williams, U.S. Department of Energy, DOE/NE, 19901 Germantown Road, Germantown, MD 20874

114. R. Williams, Electric Power Research Institute, 3412 Hillview Avenue, Palo Alto, CA 94303

115. S. D. Wiltshire, J. K. Associates, 4303 North 11th Strect, Arlington, VA 22201

116. J. Youngblood, U.S. Nuclear Regulatory Commission, Washington, DC 20585

117-313. Given distribution as shown in TIC-4500 in Category UC 510, 810 


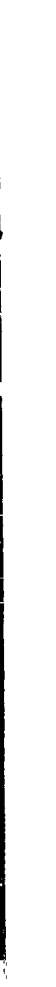

